\title{
Valproic acid triggers erythro/megakaryocyte lineage decision through induction of GFI1B and MLLT3 expression
}

\author{
Roberta Zini $^{\mathrm{a}}$, Ruggiero Norfo ${ }^{\mathrm{a}}$, Francesco Ferrari ${ }^{\mathrm{b}}$, Elisa Bianchi ${ }^{\mathrm{a}}$, Simona Salati ${ }^{\mathrm{a}}$, \\ Valentina Pennucci ${ }^{\mathrm{a}}$, Giorgia Sacchi ${ }^{\mathrm{a}}$, Chiara Carboni ${ }^{\mathrm{c}}$, Giovanni Battista Ceccherelli ${ }^{\mathrm{c}}$, \\ Enrico Tagliafico ${ }^{\mathrm{b}}$, Sergio Ferrari ${ }^{\mathrm{b}}$, and Rossella Manfredini ${ }^{\mathrm{a}}$ \\ on behalf of the AGIMM Investigators
}

\begin{abstract}
${ }^{\mathrm{a}}$ Centre for Regenerative Medicine, Department of Biomedical Sciences, University of Modena and Reggio Emilia, Modena, Italy; ${ }^{\mathrm{b}}$ Center for Genome Research, Department of Biomedical Sciences, University of Modena and Reggio Emilia, Modena, Italy; ${ }^{\mathrm{c} B l o o d}$ Transfusion Service, Azienda Ospedaliero-Universitaria di Modena, Policlinico, Modena, Italy
\end{abstract}

(Received 15 December 2011; revised 1 August 2012; accepted 5 August 2012)

\begin{abstract}
Histone deacetylase inhibitors represent a family of targeted anticancer compounds that are widely used against hematological malignancies. So far little is known about their effects on normal myelopoiesis. Therefore, in order to investigate the effect of histone deacetylase inhibitors on the myeloid commitment of hematopoietic stem/progenitor cells, we treated $\mathrm{CD34}^{+}$ cells with valproic acid (VPA). Our results demonstrate that VPA treatment induces H4 histone acetylation and hampers cell cycle progression in $\mathrm{CD34}^{+}$cells sustaining high levels of CD34 protein expression. In addition, our data show that VPA treatment promotes erythrocyte and megakaryocyte differentiation. In fact, we demonstrate that VPA treatment is able to induce the expression of growth factor-independent protein $1 B$ (GFIB) and of mixedlineage leukemia translocated to chromosome 3 protein (MLLT3), which are crucial regulators of erythrocyte and megakaryocyte differentiation, and that the up-regulation of these genes is mediated by the histone hyperacetylation at their promoter sites. Finally, we show that GFI1B inhibition impairs erythroid and megakaryocyte differentiation induced by VPA, while MLLT3 silencing inhibits megakaryocyte commitment only. As a whole, our data suggest that VPA sustains the expression of stemness-related markers in hematopoietic stem/progenitor cells and is able to interfere with hematopoietic lineage commitment by enhancing erythrocyte and megakaryocyte differentiation and by inhibiting the granulocyte and mono-macrophage maturation. (C) 2012 ISEH - Society for Hematology and Stem Cells. Published by Elsevier Inc.
\end{abstract}

Chromatin modifications such as histone acetylation and DNA methylation are important mechanisms of gene expression control [1,2]. More in detail, specific histone acetylation and DNA methylation patterns are known to be associated with modification of chromatin structure and transcriptional regulation [3]. Histone deacetylation

Offprint requests to: Rossella Manfredini, Ph.D., Centre for Regenerative Medicine, Department of Biomedical Sciences, University of Modena and Reggio Emilia, Via Gottardi 100, 41125 Modena, Italy; E-mail: manfredini.rossella@unimore.it and Sergio Ferrari, M.D., Centre for Genome Research, Department of Biomedical Sciences, University of Modena and Reggio Emilia, Via Campi 287, 41125 Modena, Italy; E-mail: sergio.ferrari@unimore.it

Supplementary data related to this article can be found online at http:// dx.doi.org/10.1016/j.exphem.2012.08.003. and DNA methylation of promoters have been correlated to the negative regulation of gene expression, while inhibition of both histone deacetylation and DNA methylation is able to revert the silencing effect.

Given the aberrant expression and/or inappropriate activation of histone deacetylases (HDACs) and DNA methyltransferases in tumors, compounds targeting such enzymes have recently generated great interest as anticancer drugs [4]. HDAC inhibitors are able to modify chromatin conformation by causing the acetylation of core histone proteins; this can lead to modulation of gene expression patterns involved in cell growth, differentiation, and apoptosis [5]. In addition, HDACs can also influence transcription-independent events by acetylation of nonhistone targets involved in cell proliferation and death, such as glycogen synthase kinase (GSK) $3 \alpha$ and $\beta$, Akt, extracellular signal-regulated kinase (ERK) 
pathway, phosphoinositol pathway, tricarboxylic acid cycle, $\gamma$-aminobutyric acid (GABA), and the oxidative phosphorylation system [6].

Histone modifications have also been implicated in stem cell maintenance and differentiation. For the first time, Milhem et al. demonstrated that HDAC inhibitors, such as trichostatin, could be used to alter primitive hematopoietic stem/ progenitor cells (HSPCs) fate in vitro [7]. Several authors confirmed the effect of HDAC inhibitors on the self-renewal capacity of hematopoietic stem cells (HSCs) [8-10].

Valproic acid (VPA) is an HDAC inhibitor previously shown to promote $\mathrm{CD}^{+} 4^{+}$cells self-renewal $[11,12]$. In addition, Seet et al. demonstrated a higher engraftment in nonobese diabetic/severe combined immune-deficient mice (NOD-SCID) for VPA-treated compared with untreated cells [13]. Consistently, VPA has been demonstrated to increase CXCR4 expression in HSPCs [14]. Recently, Bartels et al. have shown that HDAC inhibition impairs granulocyte colony-stimulating factor-driven (G-CSF) myeloid differentiation in vitro [15], while Liu et al. demonstrated that VPA promotes interleukin-3-mediated megakaryopoiesis and erythropoiesis $[16,17]$.

Leukemic fusion proteins, such as PML/RAR $\alpha$ and AML-1/ETO, form a complex with HDACs with higher affinitiy than their normal counterparts and aberrantly suppress the expression of genes required for cell differentiation and growth control, leading to the transformation of hematopoietic progenitor cells $[18,19]$. Therefore, HDACs are considered direct targets of treatment in these cases. A variety of small compounds that inhibit HDAC activity have been developed and tested as therapeutic agents for hematologic malignancies, including AML with fusion gene products and solid tumors [20].

Several authors demonstrated that HDAC inhibitors induced differentiation and apoptosis in a variety of malignant cells in vitro [21]. As a consequence, the activity of numerous HDAC inhibitors, either as single agent or in combination with other anticancer agents, has been tested in clinical trials in subjects with solid tumors, leukemia, and myelodysplastic syndromes [5,22-30].

Despite the established therapeutic use of HDAC inhibitors, relatively little is known about the role of VPA interference on normal myelopoiesis [31]. To this end, human HSPCs were treated with HDAC inhibitor VPA, and the proliferation and differentiation capacities of VPA-treated cells were studied. In order to investigate modulation of gene expression after VPA treatment, we performed a gene expression profile of VPA-treated cells using DNA microarray technology.

In this article, we show that VPA induces the expression of several genes involved in HSC self-renewal. We also demonstrate that VPA enhances erythrocyte and megakaryocyte differentiation of $\mathrm{CD} 34^{+}$cells at the expense of granulocyte and mono-macrophage ones. Here we identified a molecular mechanism explaining the effect of VPA on $\mathrm{CD} 34^{+}$cell lineage commitment. In fact, we demonstrated the induction of growth factor-independent protein 1B (GFI1B) [32] and mixed-lineage leukemia translocated to chromosome 3 protein (MLLT3) [33], master gene regulators of erythrocyte/megakaryocyte commitment via hyperacetylation of histone proteins localized in their promoters in VPA-treated cells. Finally, we showed that a small interfering RNA (siRNA)-mediated silencing of GFI1B was able to impair erythroid and megakaryocyte differentiation induced by VPA treatment, while a siRNA-mediated silencing of MLLT3 inhibits megakaryopoiesis only.

These results provided, for the first time, an important molecular support to explain the biological effect of VPA treatment on proliferation, self-renewal, and differentiation in human HSPCs, and improved knowledge on activity of antineoplastic drug VPA on normal hematopoiesis.

\section{Materials and methods}

$\mathrm{CD}_{3} 4^{+}$stem/progenitor cell purification

Human $\mathrm{CD} 4^{+}$cells were purified on donor's informed consent from umbilical cord blood samples collected after normal deliveries, according to the institutional guidelines for discarded material, as described previously [34].

\section{Cell culture and treatment}

VPA (Sigma-Aldrich, St Louis, MO, USA) was dissolved in water at a concentration of $50 \mathrm{mg} / \mathrm{mL}$.

$\mathrm{CD} 4^{+}$hematopoietic cells were seeded in 24-well plates at a density of $5 \times 10^{5}$ cell $/ \mathrm{mL}$ in Iscove's modified Dulbecco's medium (Euroclone, Celbio, Milano, Italy) supplemented with $20 \%$ heat-inactivated human serum (Lonza, Milano, Italy), 1 $\mathrm{mM}$ L-glutamine (Euroclone), stem cell factor $(50 \mathrm{ng} / \mathrm{mL})$, Flt3 ligand $(50 \mathrm{ng} / \mathrm{mL})$, thrombopoietin $(20 \mathrm{ng} / \mathrm{mL})$, interleukin-6 (10 ng/mL), and interleukin-3 (10 ng/mL) (all from R\&D Systems, Minneapolis, MN, USA). CD $34^{+}$cells were initially maintained in the media described here and incubated at $37^{\circ} \mathrm{C}$ in humidified atmosphere containing $5 \% \mathrm{CO}_{2}$. In preliminary experiments, $\mathrm{CD}_{3} 4^{+}$cells were treated with different VPA concentrations to assess which dose could get a substantial increase in histone $\mathrm{H} 4$ acetylation coupled with high viability (>90\%), monitored by Trypan blue exclusion assay. Among tested doses $(50-600 \mu \mathrm{g} / \mathrm{mL}), 400 \mu \mathrm{g} / \mathrm{mL}$ resulted the best one, coupling a significant higher histone $\mathrm{H} 4$ acetylation without relevant toxicity (Supplementary Figure E1; online only, available at www.exphem.org). Then, after 24 hours of preactivation in the culture conditions described, cells were treated with $400 \mu \mathrm{g} / \mathrm{mL}$ VPA and the culture was monitored for additional 9 days.

\section{Analysis of histone acetylation}

Acetylated histone H4 intracellular staining was performed 24 and 48 hours after VPA treatment using LEUCOPERM cell permeabilization kit (AbD Serotec, MorphoSys, Martinsried, Germany). Briefly, $10^{5}$ cells were fixed for $15 \mathrm{~min}$ at room temperature in reagent $\mathrm{A}$ and subsequently fixed in $100 \%$ methanol for $10 \mathrm{~min}$ at $4^{\circ} \mathrm{C}$. Then fixed cells were washed with phosphate-buffered saline and permeabilized with reagent $\mathrm{B}$ for $30 \mathrm{~min}$ at room temperature with rabbit anti-acetyl-histone $\mathrm{H} 4$ polyclonal antiserum (\#06-866; Upstate, Lake Placid, NY, USA). Finally, cells were washed with 
phosphate-buffered saline and incubated with fluorescein isothiocyanate goat anti-rabbit IgG F( $\left.\mathrm{ab}^{\prime}\right)_{2}$ fragment (Sigma).

Statistical analysis

Statistics used for data analysis were based on the two-tailed Student's $t$ test for average comparison in paired samples; in particular, VPA CD34 ${ }^{+}$sample and control (CTR) $\mathrm{CD}^{+} 4^{+}$were compared. Data were analyzed by Microsoft Excel Software (version 2007, Redmond, WA, USA) and $p<0.05$ was considered significant.

\section{Results}

Effects of VPA treatment on $C D 34^{+}$cell proliferation and histone acetylation levels

The expression level of acetylated histone $\mathrm{H} 4$ on CTR and VPA-treated $\mathrm{CD} 34^{+}$cells was assessed by immunofluorescence analysis 24 and 48 hours after treatment (Fig. 1). Flow cytometric analysis showed a significant increase in acetylated $\mathrm{H} 4$ in VPA-treated $\mathrm{CD} 34^{+}$cells compared to control, as detailed in Figure 1A. VPA-treated CD34 ${ }^{+}$cells showed the maximum level of acetylated $\mathrm{H} 4$ expression and the maximum difference from CTR cells 48 hours after treatment (Fig. 1B); consequently, this time point has been chosen to analyze the gene expression profile of CTR and VPA-treated CD $34^{+}$cells.

To study the effect of VPA on $\mathrm{CD} 34^{+}$cell proliferation, we performed flow cytometric analysis of the cell cycle using a propidium iodide staining technique. Cell cycle analysis showed, after 48 hours of VPA treatment, a significant increase of cell fraction in the $\mathrm{G}_{0}-\mathrm{G}_{1}$ phase of the cell cycle, while significant differences in apoptotic cell percent were not detected, as shown in Figure 2.

\section{Effects of VPA treatment on CD34 expression and}

differentiation capacity of $\mathrm{CD} 34^{+}$cells

The expression level of CD34 antigen on CTR and VPAtreated $\mathrm{CD} 34^{+}$cells was assessed after 2 and 6 days of treatment. Flow cytometric analysis showed a physiological decrease of CD34 expression in CTR cells at day 6 of treatment, while in VPA-treated cells CD34 expression was maintained at high levels, as detailed in Figure 3A.

Flow cytometric analysis of lineage differentiation markers performed at day 6 of treatment showed in VPA-treated $\mathrm{CD} 34^{+}$cells a significant increase in expression levels of glycophorin A (GPA) and CD41, erythroid and megakaryocytic markers, respectively; on the contrary, granulocyte (CD66b, CD15, and myeloperoxidase) and mono-macrophage (CD14 and CD163) specific markers showed a significant decrease in VPA-treated cells as compared with CTR cells (Fig. 3B). Morphological analysis performed at day 9 of treatment revealed that VPAtreated cells had a strong enrichment in erythrocyte and megakaryocyte precursors at different stages of maturation,
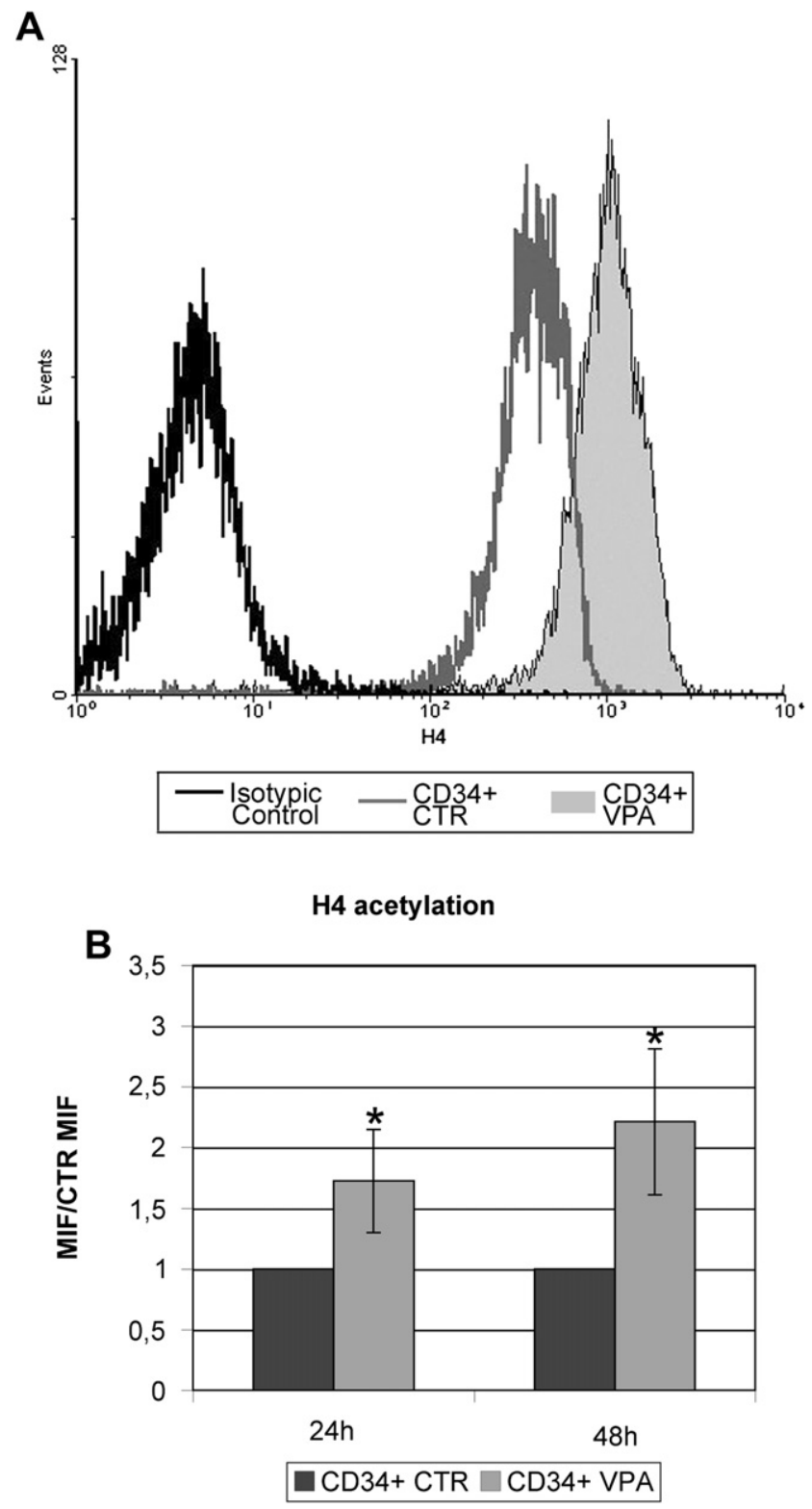

Figure 1. Flow cytometric analysis of tetracetylated histone $\mathrm{H} 4$ in $\mathrm{CD} 34^{+}$ CTR and VPA-treated cells. (A) Histogram overlay of a representative experiment at 48 hours of treatment. (B) Results of statistical analysis on the percentage of positive cells for tetracetylated histone $\mathrm{H} 4$ performed at 24 and 48 hours of VPA treatment. Values are reported as mean \pm 2 standard error of mean (SEM). * $p<0.05$ vs CTR. Results come from five independent experiments. $\mathrm{h}=$ hours; $\mathrm{MIF}=$ mean intensity of fluorescence.

whereas the granulocyte and monocyte elements were poorly represented compared with control (Fig. 3C).

To better characterize the effects of VPA treatment on stem/progenitor cell differentiation, $\mathrm{CD} 34^{+}$cells were plated in methylcellulose-based medium at days 2 and 6 of treatment in a set of five independent experiments. Results demonstrated that the clonogenic capacity of VPA-treated $\mathrm{CD} 34^{+}$cells was decreased, according to the interference of VPA treatment with the proliferative activity (Figures 2 and 4A and Supplementary Figure E2; online 

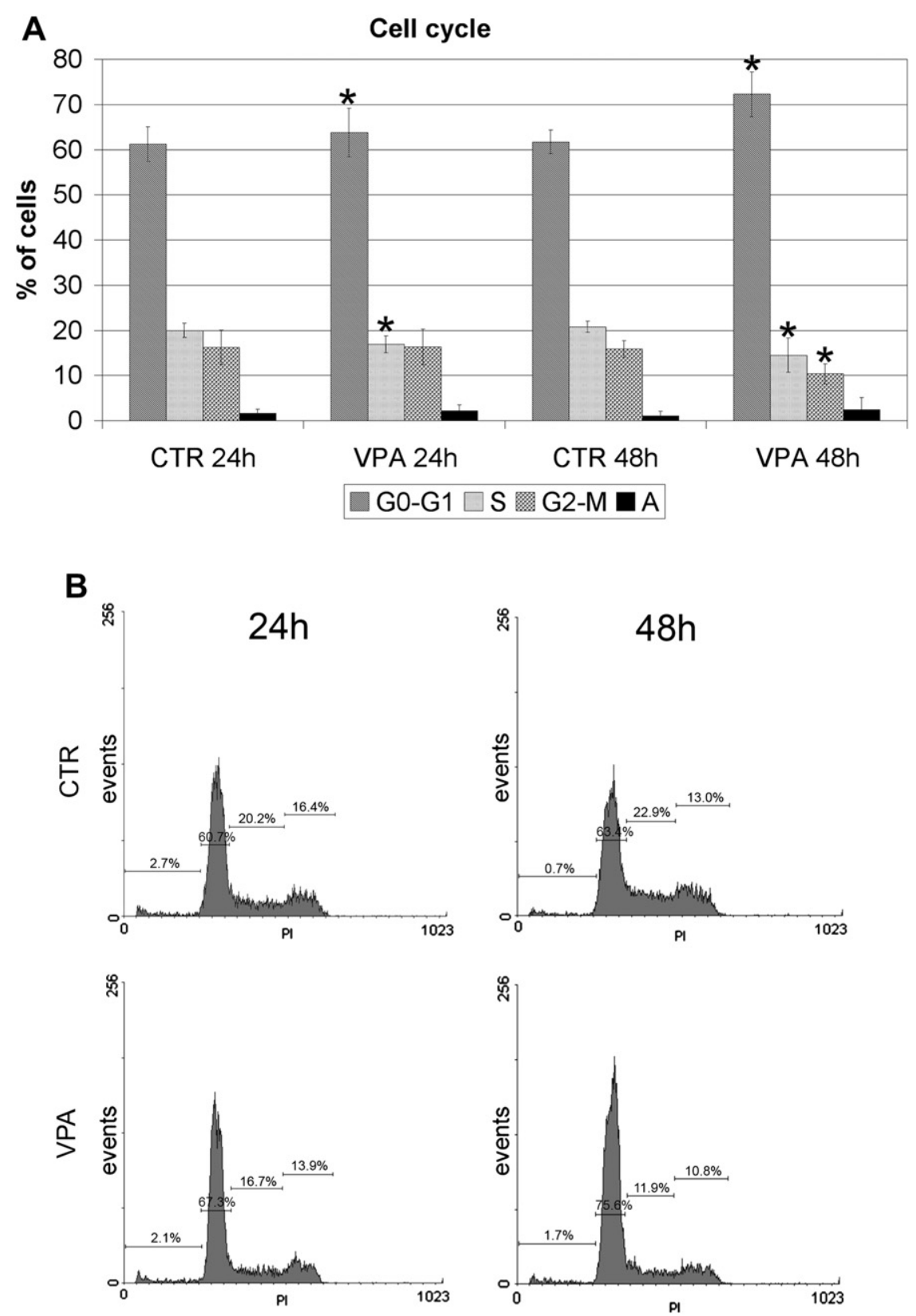

Figure 2. Evaluation of cell cycle distribution performed by propidium iodide (PI) staining in CD $34^{+}$CTR and VPA-treated cells. (A) Results are shown as percent of cells in the different phases of the cell cycle. (B) PI staining histograms of a representative experiment at 24 and 48 hours of treatment. Values are reported as mean \pm 2 standard error of mean (SEM). $* p<0.05$ vs CTR. Results come from five independent experiments. A $=$ apoptotic hypodiploid cells; $\mathrm{G}_{0}-\mathrm{G}_{1}=\mathrm{G}_{0}-\mathrm{G}_{1}$ phase cells; $\mathrm{G}_{2}-\mathrm{M}=\mathrm{G}_{2}-\mathrm{M}$ phase cells; $\mathrm{h}=$ hours; $\mathrm{S}=\mathrm{S}$ phase cells.

only, available at www.exphem.org). In addition, the methylcellulose-based clonogenic assay showed a significant increase in the percentage of burst-forming unit (BFU)-erythroid and colony-forming unit (CFU)-erythroid in VPA-treated $\mathrm{CD} 34^{+}$cells, coupled with a decrease in CFU-granulocyte (CFU-G) percentage (Fig. 4B). These results indicate that VPA treatment enhances erythroid differentiation at the expense of granulocytic lineage.

Next we examined the effect of VPA treatment on megakaryocyte differentiation using a collagen-based culture system that supports megakaryopoietic progenitor growth in vitro. For this purpose, controls and VPA-treated CD $34^{+}$cells were plated in collagen-based medium at day 2 of treatment in a set of five independent experiments. The results obtained, reported in Figure 4C, clearly indicate that VPA treatment induced a remarkable increase in CFUmegakaryocyte (CFU-MK).

Gene expression profile of VPA-treated $\mathrm{CD} 34^{+}$cells To investigate changes in gene expression induced by VPA treatment, we performed microarray analysis on CTR and VPA-treated CD $34^{+}$cells using the Affymetrix HGU133A 
A

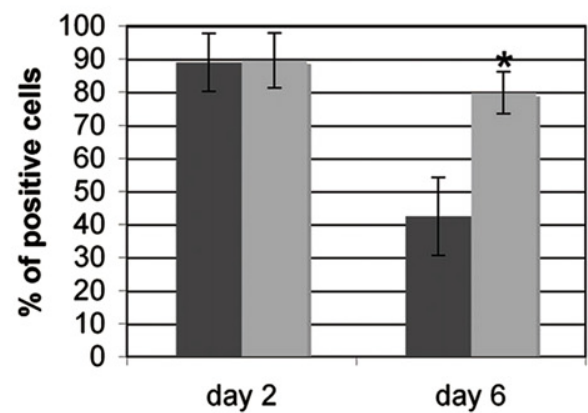

CTR CD34+
B

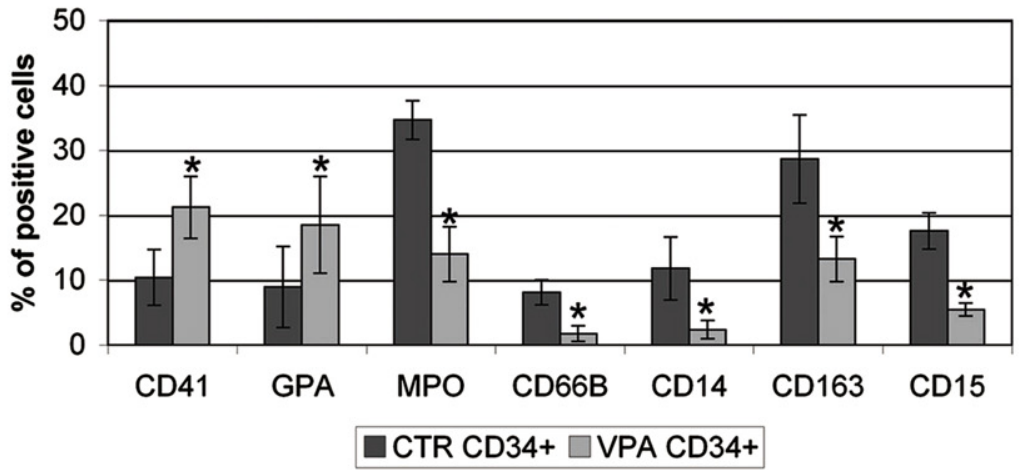

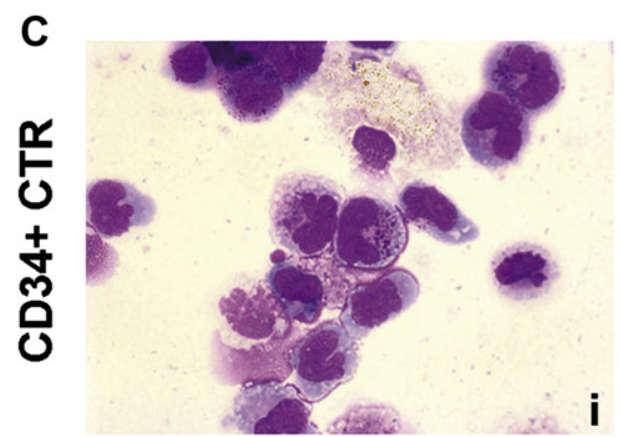
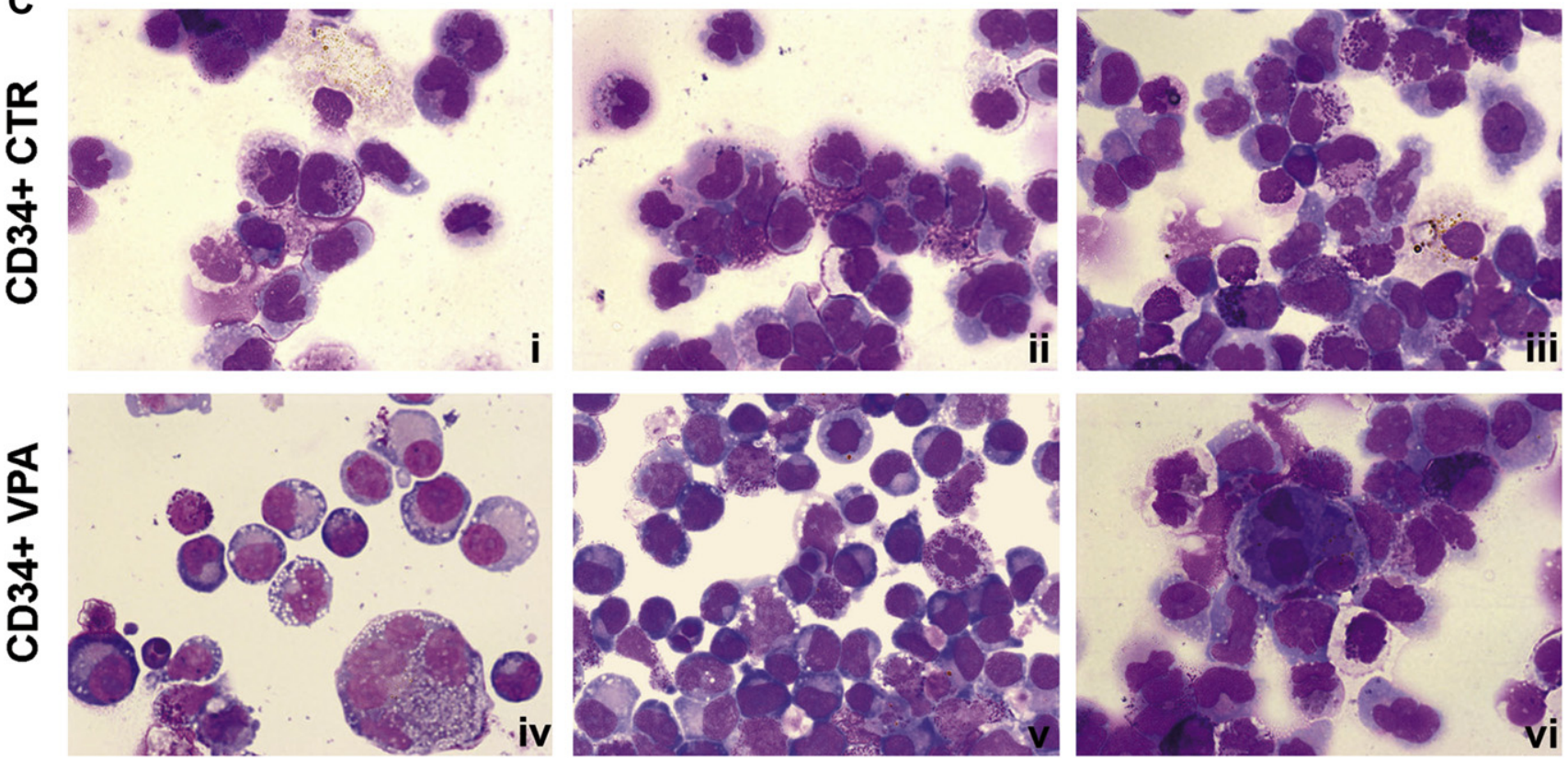

Figure 3. Effect of VPA treatment on myeloid differentiation of CD34 ${ }^{+}$cells. (A) Results of statistical analysis on the percent of positive cells for CD34 antigen performed after 2 and 6 days of VPA treatment. (B) Results of statistical analysis on the percent of positive cells for differentiation markers (GPA, CD41, CD66B, MPO, CD15, CD14, and CD163) performed by flow cytometry at day 6 of VPA treatment. (C) Morphological analysis of CD34 ${ }^{+}$CTR (i, ii, iii) and VPA (iv, v, vi) cells after May-Grünwald-Giemsa staining at day 9 of VPA treatment in a representative experiment. Magnification $\times 630$. Values are reported as mean \pm 2 standard error of mean $(\mathrm{SEM}) .{ }^{*} p<0.05$ vs CTR. Results come from four independent experiments. MPO $=$ myeloperoxidase.

GeneChip array that is able to monitor $>12,000$ transcripts. Microarray analysis was performed on pooled RNA derived from five independent experiments at 48 hours of VPA treatment.

Using the filtering procedure described in Supplementary Materials and Methods (online only, available at www. exphem.org), we identified a list of genes significantly modulated by VPA treatment. DAVID 6.7 analysis showed that the "cell differentiation," "cellular developmental process," and "cell development" Gene Ontology (GO) categories are mainly represented in the gene list of probe sets increased in VPA-treated vs CTR cells (Supplementary Table E1A; online only, available at www.exphem.org). Consistent with the differentiation process, several GO categories involved in cytoskeleton reorganization ("cytoskel- eton organization and biogenesis," "actin polymerization and/or depolymerization") and in cellular morphology ("cellular morphogenesis during differentiation," "cell projection morphogenesis") are significantly represented in the list of increased genes [35-38]. Conversely, GO categories down-regulated by VPA treatment include "positive regulation of cell proliferation," and "cell proliferation." In addition, in agreement with mono-macrophage and granulocyte commitment inhibition, many genes belonging to GO categories such as "immune response," "immune system process," and "defense response" were significantly downregulated by VPA treatment (Supplementary Table E1B; online only, available at www.exphem.org).

The study of differentially expressed genes showed that among transcripts increased in VPA-treated cells, there are 


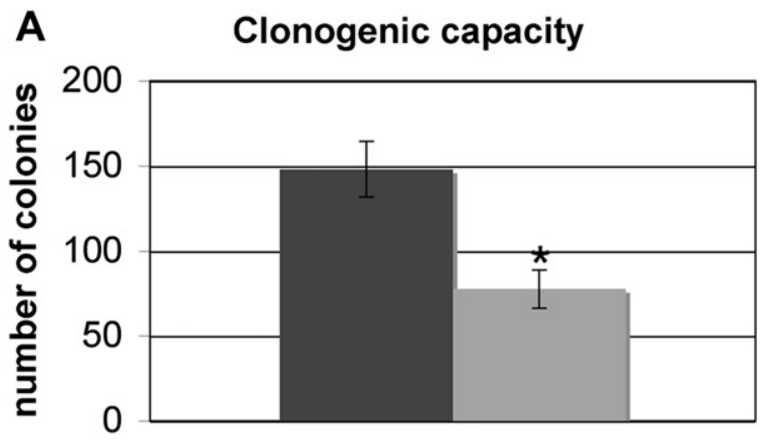

CTR CD34+
C

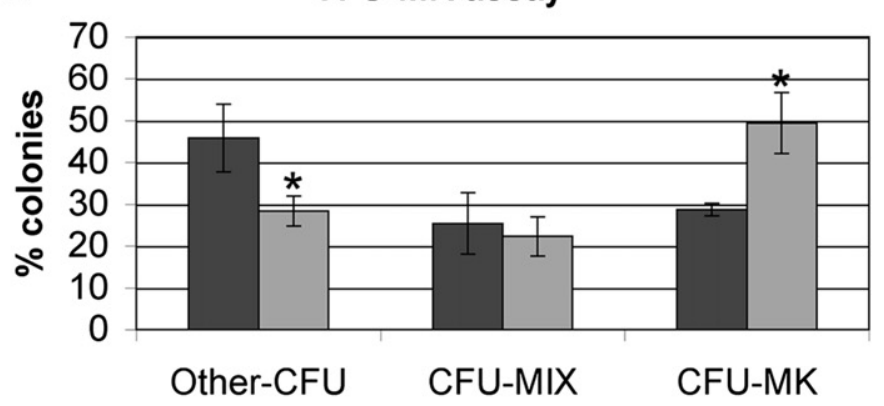

CTR CD34+ $\square$ VPA CD34+

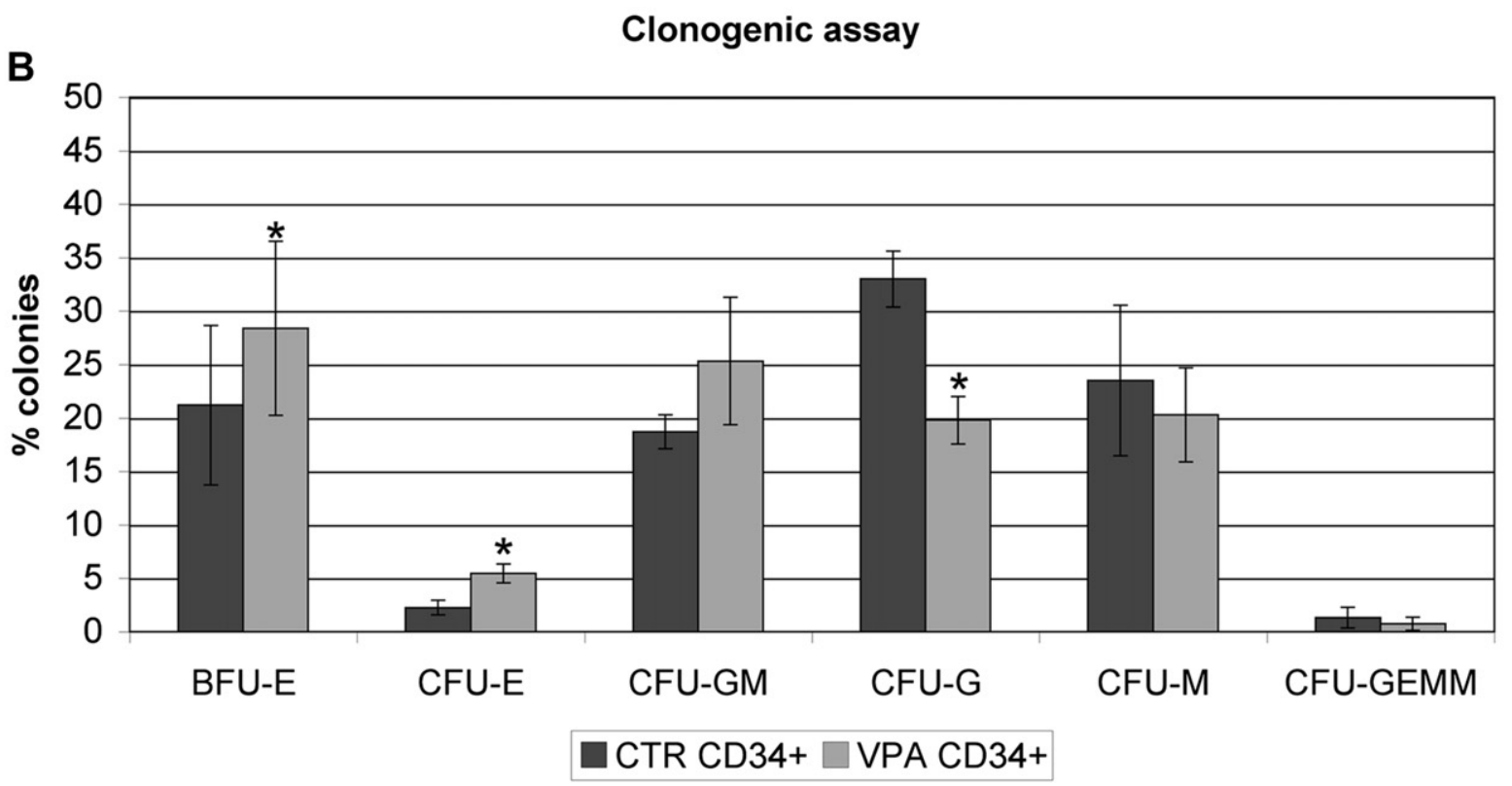

Figure 4. Clonogenic capacity of CTR and VPA-treated CD $34^{+}$cells. (A, B) Results of statistical analysis of methylcellulose-based clonogenic assay in cells plated after 48 hours of treatment with VPA and scored after 14 days. (A) Count of total colonies; (B) count of different colony types; (C) results of statistical analysis of collagen-based clonogenic assay in cells plated after 48 hours of VPA treatment and scored after 12 days. Values are reported as mean \pm 2 standard error of mean (SEM). ${ }^{*} p<0.05$ vs CTR. Results come from five independent experiments. BFU-E = burst-forming unit-erythroid; $\mathrm{E}=$ erythrocyte; $\mathrm{G}=$ granulocyte; $\mathrm{M}=$ monocyte; $\mathrm{GM}=$ granulocyte-monocyte; GEMM = granulocyte-erythrocyte-monocyte-megakaryocyte; $\mathrm{MK}=$ megakaryocyte .

cell cycle and self-renewal-related genes, such as the cell cycle inhibitor CDKN1A (p21/Cip1) [9] and the transcription factors GATA2 [39,40], LEF1, PBX1, ID1, and ID2 [41] (Fig. 5). Consistent with previous data, VPA-treated CD $34^{+}$cells preferentially expressed stemness markers like FGFR1 [42] and ABCB1 [43].

In addition, VPA treatment up-regulated key regulatory genes involved in erythrocyte and megakaryocyte differentiation; in particular, transcription factors like MLLT3 and GFI1B [32,33], that regulate early human erythroid and megakaryocytic cell fate at the bipotent erythromegakaryocytic progenitor stage, are increased by VPA treatment (Fig. 5A). As shown in Figure 5A, master regulators of erythrocyte commitment, such as GATA1, NFE2, and TAL1 [44-46], and markers of erythrocyte differentiation, such as HBE1, EPOR, EPHB4, and CD36 [21,4749], were up-regulated in VPA-treated cells. Similarly, VPA-treated $\mathrm{CD} 34^{+}$cells showed increased expression of transcription factors involved in megakaryocyte commitment, such as GATA1, RUNX1, and NFE2 [45,50,51], together with up-regulation of genes coding for platelet surface proteins, such as CD9 and CD36 [52,53] (Fig. 5A).

Among down-regulated genes, we found the myeloid transcription factor CEBPD [54], monocytic markers (CD163, STAB1, and TNFSF12), and granulocyte-specific granule proteins (myeloperoxidase, ELA2, EPX, and PRTN3) [55] (Fig. 5A). 
A

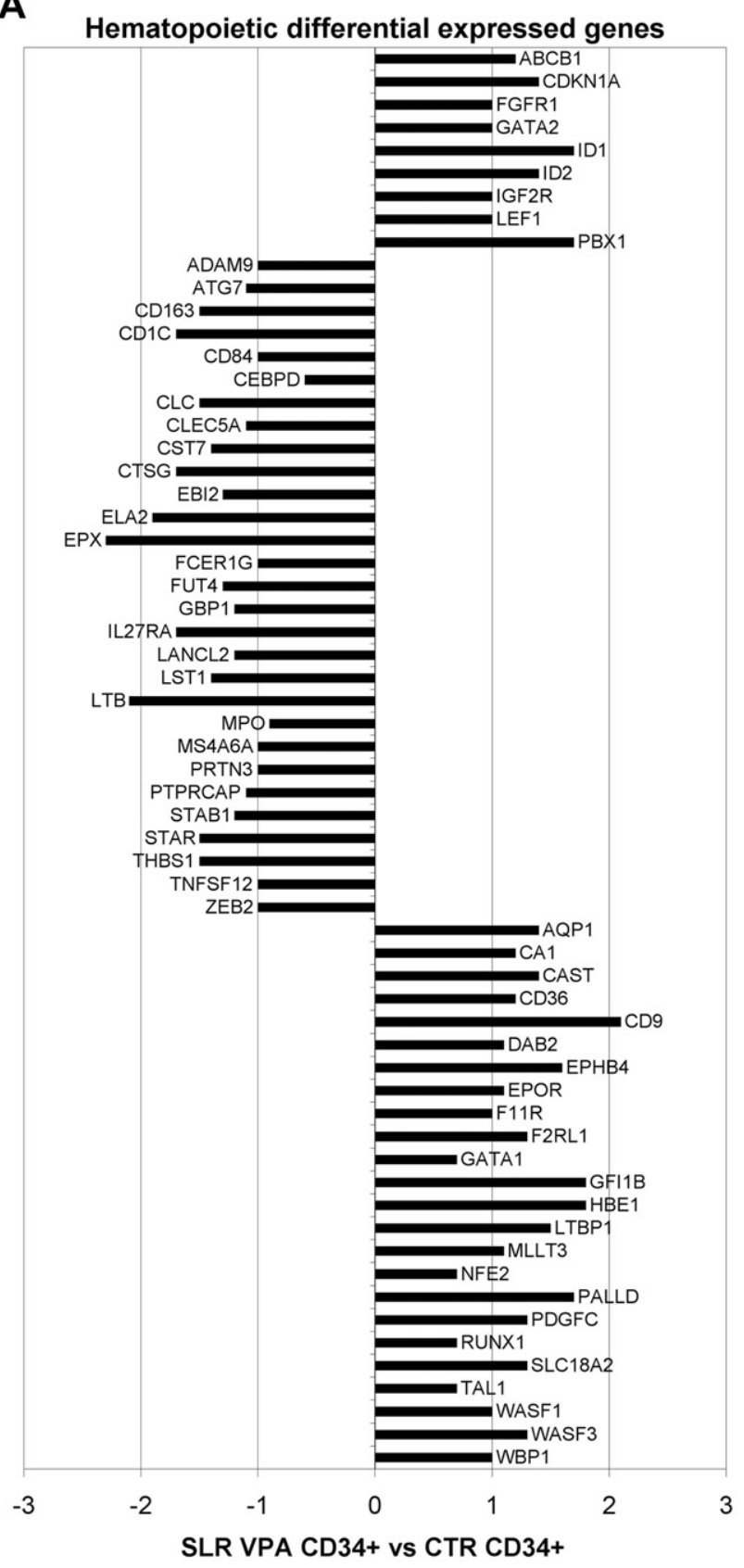

B

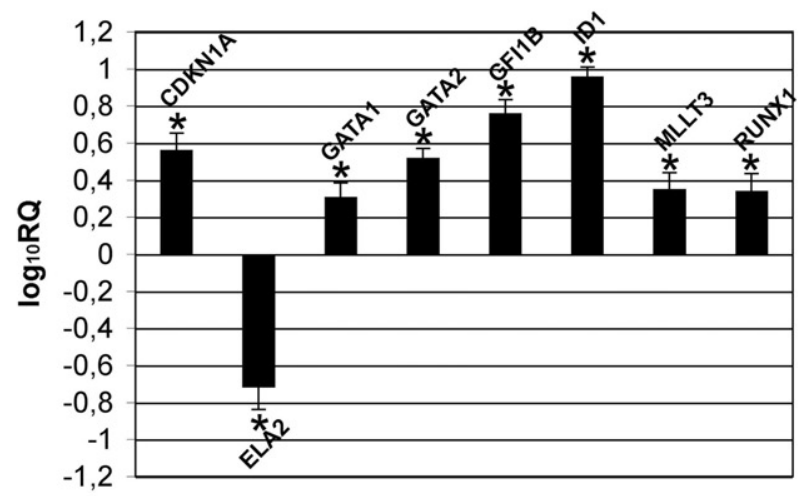

C

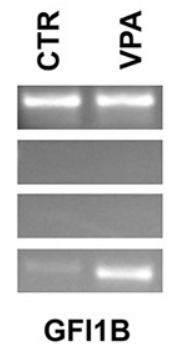

TI

No Ab

$\lg G$ H4

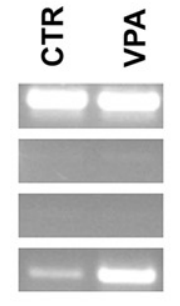

No $A b$

$\lg \mathbf{G}$

iii

MLLT3
TI

H4

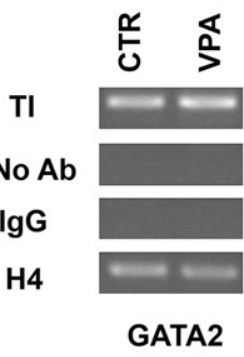

Figure 5. Changes in gene expression profile induced by VPA treatment in CD $34^{+}$cells. (A) Microarrays analysis was performed at day 2 of VPA treatment on pooled RNAs from CTR and VPA-treated CD34 ${ }^{+}$cells from five independent experiments. Changes in gene expression are reported on the $\mathrm{x}$-axis as signal $\log$ ratio (SLR). (B) Expression levels of eight genes selected as differentially expressed from microarray data. Gene expression levels were measured by RTQ-PCR starting from total RNA and were expressed as $\log _{10}$ of relative quantity [14]. Results of RTQ-PCR analysis performed at day 2 on CTR and VPA-treated CD $34^{+}$cells. Values are reported as mean \pm 2 standard error of mean (SEM). ${ }^{*} p<0.05$ vs CTR. Results come from three independent experiments. (C) Effect of VPA treatment on histone H4 acetylation status at proximal promoter regions of GFI1B (i), MLLT3 (ii), and GATA2 (iii) genes. CD34 ${ }^{+}$ cells were treated (VPA) or not (CTR) with VPA for 24 hours. Chromatin immunoprecipitation assay was performed with anti-acetyl-histone H4 antibody (H4), normal rabbit IgG (IgG), or no antibody (No Ab) and analyzed by PCR using primers corresponding to regions on GATA2, GFI1B, and MLLT3 promoters. A sample representing total input chromatin (TI) was included in the PCR analysis. For each gene, the figure shows a representative case out of three that gave similar results. Data shown are for 30 PCR cycles. PCR products were analyzed by $2 \%$ agarose-ethidium bromide gel electrophoresis.

As a whole, microarray data provide a strong molecular support for the biological effect promoted by VPA treatment on the proliferation, self-renewal, and differentiation capacities of hematopoietic stem/progenitor cells.
In order to confirm microarray data, we carried out a TaqMan real-time quantitative polymerase chain reaction (RTQ-PCR) analysis on a validation set of transcripts selected among the differentially expressed genes in 
VPA-treated vs CTR CD $34^{+}$cells. All genes analyzed by RTQ-PCR showed the same expression pattern obtained by microarray analysis (Fig. 5B).

\section{Chromatin immunoprecipitation on GATA2, MLLT3, and GFIIB regulatory sites}

To evaluate whether chromatin-remodeling events are responsible for the biological effects exerted by VPA treatment, we investigated the acetylation status of histone $\mathrm{H} 4$ on the proximal promoter regions of GATA2, GFI1B, and MLLT3 genes by chromatin immunoprecipitation analysis (Fig. 5C). Upon 24 hours of VPA treatment, promoter regions of GFI1B and MLLT3 genes appeared hyperacetylated as detailed in Figure 5Ci and ii. On the contrary, no modulation of acetylation level was detected on GATA2 promoter (Fig. 5Ciii). Thus, the modulation of GFI1B and MLLT3 expression, reported after VPA treatment, positively correlates with the acetylation status of histone $\mathrm{H} 4$ on their proximal promoter regions, suggesting that VPA is able to induce changes in GFI1B and MLLT3 expression by enhancing the acetylation level of histone $\mathrm{H} 4$.

\section{GFIIB and MLLT3 silencing in VPA-treated CD34 ${ }^{+}$ cells}

In order to confirm the role of GFI1B and MLLT3 in VPAinduced erythrocyte/megakaryocyte commitment, we silenced their expression in VPA-treated CD $34^{+}$cells using the siRNA approach. $\mathrm{CD} 34^{+}$cells were nucleofected with a mixture of three siRNAs targeting GFI1B and/or MLLT3 messenger RNA (Supplementary Table E2; online only, available at www.exphem.org) and with a nontargeting siRNA as a negative control (NC). After first nucleofection, transfected cells were left untreated or treated with $400 \mu \mathrm{g} /$ $\mathrm{mL}$ VPA. The expression level of target genes in NC and siRNA cells was assessed by RTQ-PCR 24 hours after the third nucleofection. Figure 6A shows that GFI1B messenger RNA was down-regulated in siRNA-treated/ VPA-untreated samples sGFI1B (GFI1B siRNA) and sG+sM (GFI1B siRNA+MLLT3 siRNA), demonstrating the efficiency of gene inhibition strategy. On the other hand, GFI1B was up-regulated in the same samples treated with VPA (sGFI1B VPA and sG+sM VPA) and in $\mathrm{NC}+\mathrm{VPA}$-treated sample.

At the same time, MLLT3 expression was downregulated in MLLT3 siRNA-treated/VPA-untreated samples (sMLLT3, sG+sM) and slightly down-regulated in siRNA+VPA-treated samples (sMLLT3 VPA and sG+sM VPA) (Fig. 6B). These data confirm that VPA is able to increase GFI1B and MLLT3 expression.

The clonogenic activity of untreated and VPA-treated sGFI1B and/or sMLLT3 cells was evaluated by means of methylcellulose- and collagen-based clonogenic assays. Methylcellulose assay highlighted that GFI1B silencing induced a remarkable decrease in the percentage of erythroid (CFU-erythroid and BFU-erythroid) colonies also in VPA-treated cells, whereas MLLT3 siRNA did not significantly affect the number of erythroid colonies (Fig. 6C). $\mathrm{CD} 41^{+}$colony scoring in collagen-based assay showed that both GFI1B and MLLT3 silencing reduced the number of CFU-megakaryocyte in untreated and VPA-treated samples (Fig. 6D). As shown in Figure 6E, flow cytometric analysis at day 5 after third nucleofection confirmed that GFI1B silencing impairs erythrocyte and megakaryocyte commitment as demonstrated by reduced expression of GPA and CD41 both in untreated and VPAtreated GFI1B-silenced cells. On the contrary, MLLT3 silencing affected only megakaryocyte commitment, as highlighted by CD41 down-regulation in both untreated and VPA-treated SMLLT3 cells.

\section{Discussion}

VPA has been used as an anticonvulsant for decades, but recently cancer treatment has become a new field of application for this drug [5,23,56]. In fact, in 2001, the antineoplastic effect of VPA was correlated to the inhibitory activity on HDACs [57], and subsequently it was demonstrated that VPA is able to induce differentiation and apoptosis in a variety of malignant cells in vitro [21]. In particular, studies in patients with advanced myeloid leukemia and myelodysplastic syndromes have shown that treatment with VPA, as monotherapy or in combination with retinoic acid, results in reduction of malignant blast cell number and hematological improvement [24-27]. Although clinical use of VPA in hematological malignancies is rapidly increasing, little is known about the specific effects of these HDAC inhibitors and molecular targets in normal hematopoietic cells.

In order to study the biological effects of VPA treatment on normal hematopoiesis, $\mathrm{CD} 34^{+}$cells were treated with VPA and proliferation/differentiation abilities were evaluated. First, we showed that VPA was able to increase the histone acetylation levels (Fig. 1). Evaluation of DNA content by propidium iodide staining and cytofluorimetric analysis, shown in Figure 2, demonstrated that VPA treatment induced an arrest in the $G_{0} / G_{1}$ phase of the cell cycle. Interestingly, VPA-treated cells maintained high CD34 expression (Fig. 3A) after 6 days of treatment, while the control sample underwent physiologic down-regulation of CD34 protein. These results are in agreement with Bartels et al., who demonstrated that VPA is able to maintain HSCs in vitro through inhibition of granulocyte differentiation [15]. In addition, our data confirm the results obtained by De Felice et al. [11], which showed that the lower rate of proliferation of VPA-treated cells was correlated with expansion of the stem cell compartment, as demonstrated by expression of the CD34, which was maintained at elevated level up to 7 days of liquid culture [12].

To characterize the ability of VPA to interfere with HSC commitment, expression levels of myeloid differentiation 

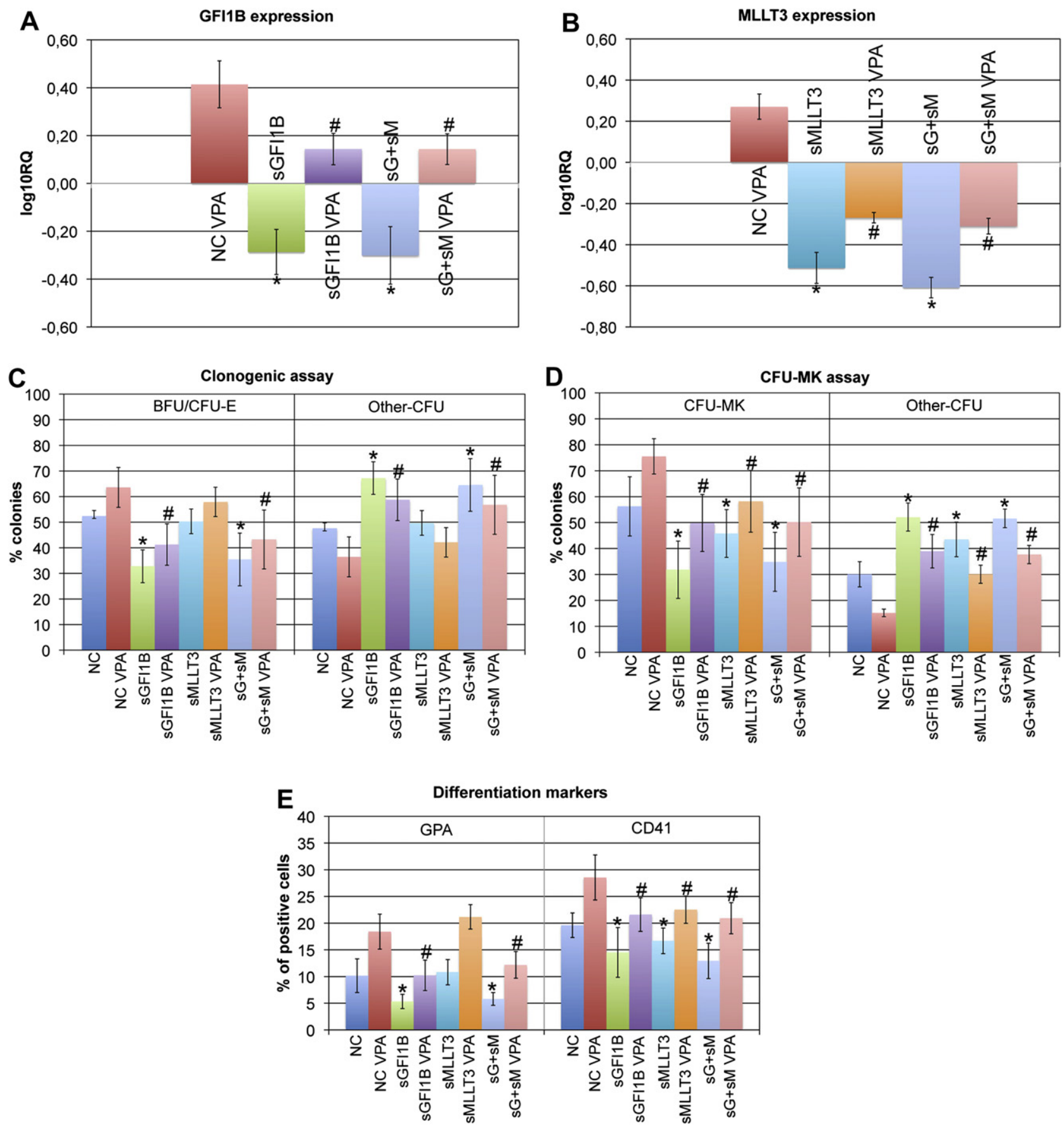

Figure 6. GFI1B and MLLT3 inhibition through siRNA in VPA CD34 ${ }^{+}$cells. (A, B) Gene expression of GFI1B and MLLT3 was measured by RTQ-PCR starting from total RNA and was expressed as $\log _{10}$ of relative quantity. Expression levels have been normalized on the sample treated with NC siRNA. Results of RTQ-PCR analysis performed at 24 hours after third nucleofection on CTR and VPA-treated CD34 ${ }^{+}$cells. (C) Results of statistical analysis of methylcellulose-based clonogenic assay in CTR and VPA cells plated at 48 hours after third nucleofection and scored after 14 days. (D) Results of statistical analysis of collagen-based clonogenic assay in CTR and VPA cells plated at 48 hours after third nucleofection and scored after 12 days. (E) Results of statistical analysis on the percent of positive cells for differentiation markers (GPA, CD41) performed by flow cytometry at day 5 after third nucleofection. Values are reported as mean \pm 2 standard error of mean (SEM). ${ }^{*} p<0.05$ vs NC CTR. ${ }^{\#} p<0.05$ vs NC VPA. Statistical analysis of NC versus NC VPA comparison is not shown. Results come from five independent experiments. BFU-E = burst-forming unit-erythroid; $\mathrm{MK}=$ megakaryocyte; sGFI1B $=$ siRNA anti-GFI1B; sG+sM = siRNA anti-GFI1B + siRNA MLLT3; SMLLT3 = siRNA anti-MLLT3.

markers were evaluated in VPA-treated vs untreated cells. As detailed in Figure 3B, VPA-treated cells showed higher expressions of erythroid marker GPA and of megakaryo- cytic marker CD41; on the contrary, expression levels of granulocyte (CD66B, myeloperoxidase, and CD15) and mono-macrophage (CD14 and CD163) specific markers 
resulted in decreased VPA-treated cells compared to control. Morphological analysis (Fig. 3C) confirmed these results, showing an enrichment in erythroid and megakaryocyte precursors in VPA-treated samples, while granulocyte and mono-macrophage elements were poorly represented.

We observed a decreased clonogenic capacity in VPAtreated cells (Figure 4A and Supplementary Figure E2; online only, available at www.exphem.org), according to interference of VPA with the proliferative activity [11]. Methylcellulose clonogenic assay results correlated with cytofluorimetric and morphological analysis, showing a significant increase in erythroid colonies, coupled with a remarkable decrease in granulocytic colonies (Fig. 4B). At the same time, the collagen-based clonogenic assay, supporting in vitro megakaryocyte progenitors growth, demonstrated that VPA treatment induces a significant increase in CFU-megakaryocyte (Fig. 4C), consistent with increased CD41 expression shown in liquid culture (Fig. 3B). Therefore, our results clearly demonstrated that VPA treatment favors HSPCs differentiation along the erythroid and megakaryocytic lineages at the expense of granulocyte and mono-macrophage lineages $[16,31]$.

Thereafter, in order to identify the molecular mechanisms underlying the biological effects on the proliferation and differentiation capacity of $\mathrm{CD} 34^{+}$cells reported here, we performed a gene expression profile of untreated and VPA-treated cells by means of Affymetrix DNA microarray platform.

In VPA-treated cells, microarray data analysis showed the up-regulation of several transcription factors involved in HSC self-renewal, such as GATA2, LEF1, PBX1, ID1, and ID2 [39-41], which is in agreement with the persistent expression of stemness markers, such as CD34 (Fig. 3A), FGFR1, and ABCB1 (Fig. 5) [42,43].

In addition, VPA induced the expression of erythroid and megakaryocytic markers, while mono-macrophage and granulocyte ones were decreased. Noteworthy, among upregulated genes in VPA-treated cells, we found several transcription factors involved in erythrocyte and megakaryocyte lineage commitment [44-46,50,51]; of particular interest are GFI1B and MLLT3, two master regulators of early human erythroid and megakaryocytic commitment at the bipotent erythro-megakaryocytic progenitor stage [32,33], whose up-regulation could explain the expansion of the erythro-megakaryocytic lineage in response to VPA treatment.

Therefore, for the first time, microarray data provided strong insights into the molecular mechanisms underlying the effects exerted by VPA on self-renewal and lineage commitment of HSPCs.

Finally, we demonstrated that VPA induces expression of GFI1B and MLLT3 genes through HDACs inhibition; in fact, chromatin immunoprecipitation analysis showed higher acelylation levels of histone $\mathrm{H} 4$ set on the proximal promoter regions of these genes (Fig. 5C). GFI1B siRNA-mediated silencing produces an impairment of erythrocyte and megakaryocyte differentiation induced by VPA treatment, whereas MLLT3 siRNA-mediated silencing affects only the VPA-induced megakaryocyte commitment (Fig. 6).

\section{Conclusions}

Our data demonstrate that epigenetic modifications induced by the HDAC inhibitor VPA in human CD34 ${ }^{+}$ HSPCs were able to affect the expression of regulatory genes involved in myeloid lineage choice, promoting the erythro-megakaryocytic lineage and inhibiting the monogranulocytic one through the increase of GFI1B and MLLT3 expression. Our results are in agreement with previous in vitro experiments performed on cells isolated from myelodysplastic syndrome patients [16], contributing to the definition of the molecular mechanism underlying the effects exerted by VPA treatment on normal HSPCs.

\section{Funding disclosure}

This work was supported by the Italian Ministry of University \& Research (Progetti di Ricerca di Interesse Nazionale, PRIN) 2008, Project “Tecnopolo" of Regione Emilia Romagna and Associazione Italiana per la Ricerca sul Cancro (AIRC, Milano), project \# 12055, and "Special Program Molecular Clinical Oncology 5x1000" to AGIMM (AIRCGruppo Italiano Malattie Mieloproliferative), project number \#1005. A detailed description of the AGIMM project is available at http://www.progettoagimm.it. R.Z. is the recipient of a fellowship from Regione Emilia-Romagna (Progetti di Ricerca Università-Regione Emilia Romagna, Progetto Medicina Rigenerativa, 2007). R.N. is the recipient of a fellowship from "Collegio Ghislieri" Foundation.

\section{Acknowledgments}

Author contributions: R.Z. and R.N. performed VPA treatment and biological effects monitoring; F.F. performed microarray data analysis; E.T. contributed to microarray data analysis and wrote the paper; G.B.C. and C.C. supplied cord blood samples and performed $\mathrm{CD}^{+}{ }^{+}$isolation; E.B. and S.S. performed CHIP experiments; V.P. and G.S. performed siRNA experiments. R.M. and S.F. designed the research and wrote the paper. R.M. was the principal investigator and takes primary responsibility for the paper.

\section{Conflict of interest disclosure}

No financial interest/relationships with financial interest relating to the topic of this article have been declared.

\section{References}

1. Reik W, Dean W, Walter J. Epigenetic reprogramming in mammalian development. Science. 2001;293:1089-1093.

2. Gibney ER, Nolan CM. Epigenetics and gene expression. Heredity (Edinb). 2010;105:4-13. 
3. Sebova K, Fridrichova I. Epigenetic tools in potential anticancer therapy. Anticancer Drugs. 2010;21:565-577.

4. Vaissiere T, Sawan C, Herceg Z. Epigenetic interplay between histone modifications and DNA methylation in gene silencing. Mutat Res. 2008;659:40-48.

5. Marks PA, Xu WS. Histone deacetylase inhibitors: potential in cancer therapy. J Cell Biochem. 2009;107:600-608.

6. Martinez-Iglesias O, Ruiz-Llorente L, Sanchez-Martinez R, Garcia L, Zambrano A, Aranda A. Histone deacetylase inhibitors: mechanism of action and therapeutic use in cancer. Clin Transl Oncol. 2008;10:395-398.

7. Milhem M, Mahmud N, Lavelle D, et al. Modification of hematopoietic stem cell fate by 5aza 2'deoxycytidine and trichostatin A. Blood. 2004;103:4102-4110.

8. Araki H, Mahmud N, Milhem M, et al. Expansion of human umbilical cord blood SCID-repopulating cells using chromatin-modifying agents. Exp Hematol. 2006;34:140-149.

9. Araki H, Yoshinaga K, Boccuni P, Zhao Y, Hoffman R, Mahmud N. Chromatin-modifying agents permit human hematopoietic stem cells to undergo multiple cell divisions while retaining their repopulating potential. Blood. 2007;109:3570-3578.

10. Bug G, Gul H, Schwarz K, et al. Valproic acid stimulates proliferation and self-renewal of hematopoietic stem cells. Cancer Res. 2005;65: 2537-2541.

11. De Felice L, Tatarelli C, Mascolo MG, et al. Histone deacetylase inhibitor valproic acid enhances the cytokine-induced expansion of human hematopoietic stem cells. Cancer Res. 2005;65:1505-1513.

12. Walasek MA, Bystrykh L, van den Boom V, et al. The combination of valproic acid and lithium delays hematopoietic stem/progenitor cell differentiation. Blood. 2012;119:3050-3059.

13. Seet LF, Teng E, Lai YS, et al. Valproic acid enhances the engraftability of human umbilical cord blood hematopoietic stem cells expanded under serum-free conditions. Eur J Haematol. 2009;82:124-132.

14. Gul H, Marquez-Curtis LA, Jahroudi N, Lo J, Turner AR, JanowskaWieczorek A. Valproic acid increases CXCR4 expression in hematopoietic stem/progenitor cells by chromatin remodeling. Stem Cells Dev. 2009;18:831-838.

15. Bartels M, Geest CR, Bierings M, Buitenhuis M, Coffer PJ. Histone deacetylase inhibition modulates cell fate decisions during myeloid differentiation. Haematologica. 2010;95:1052-1060.

16. Liu B, Ohishi K, Yamamura K, et al. A potential activity of valproic acid in the stimulation of interleukin-3-mediated megakaryopoiesis and erythropoiesis. Exp Hematol. 2010;38:685-695.

17. Chaurasia P, Berenzon D, Hoffman R. Chromatin-modifying agents promote the ex vivo production of functional human erythroid progenitor cells. Blood. 2011;117:4632-4641.

18. Lin RJ, Nagy L, Inoue S, Shao W, Miller WH Jr, Evans RM. Role of the histone deacetylase complex in acute promyelocytic leukaemia. Nature. 1998;391:811-814.

19. Wang J, Hoshino T, Redner RL, Kajigaya S, Liu JM. ETO, fusion partner in $\mathrm{t}(8 ; 21)$ acute myeloid leukemia, represses transcription by interaction with the human $\mathrm{N}-\mathrm{CoR} / \mathrm{mSin} 3 / \mathrm{HDAC} 1$ complex. Proc Natl Acad Sci U S A. 1998;95:10860-10865.

20. Xu WS, Parmigiani RB, Marks PA. Histone deacetylase inhibitors: molecular mechanisms of action. Oncogene. 2007;26:5541-5552.

21. Kuendgen A, Gattermann N. Valproic acid for the treatment of myeloid malignancies. Cancer. 2007;110:943-954.

22. Duenas-Gonzalez A, Candelaria M, Perez-Plascencia C, Perez-Cardenas E, de la Cruz-Hernandez E, Herrera LA. Valproic acid as epigenetic cancer drug: preclinical, clinical and transcriptional effects on solid tumors. Cancer Treat Rev. 2008;34:206-222.

23. Minucci S, Pelicci PG. Histone deacetylase inhibitors and the promise of epigenetic (and more) treatments for cancer. Nat Rev Cancer. 2006; 6:38-51.

24. Kuendgen A, Schmid M, Schlenk R, et al. The histone deacetylase (HDAC) inhibitor valproic acid as monotherapy or in combination with all-trans retinoic acid in patients with acute myeloid leukemia. Cancer. 2006;106:112-119.

25. Kuendgen A, Strupp C, Aivado M, et al. Treatment of myelodysplastic syndromes with valproic acid alone or in combination with all-trans retinoic acid. Blood. 2004;104:1266-1269.

26. Soriano AO, Yang H, Faderl S, et al. Safety and clinical activity of the combination of 5-azacytidine, valproic acid, and all-trans retinoic acid in acute myeloid leukemia and myelodysplastic syndrome. Blood. 2007;110:2302-2308.

27. Cimino G, Lo-Coco F, Fenu S, et al. Sequential valproic acid/all-trans retinoic acid treatment reprograms differentiation in refractory and high-risk acute myeloid leukemia. Cancer Res. 2006;66:8903-8911.

28. Shah P, Mato A, Luger SM. Valproic acid for the treatment of myeloid malignancies. Cancer. 2008;112:2324-2325. author reply 2325.

29. Kuendgen A, Bug G, Ottmann OG, et al. Treatment of poor-risk myelodysplastic syndromes and acute myeloid leukemia with a combination of 5-azacytidine and valproic acid. Clin Epigenetics. 2011;2: 389-399.

30. Candelaria M, Herrera A, Labardini J, et al. Hydralazine and magnesium valproate as epigenetic treatment for myelodysplastic syndrome. Preliminary results of a phase-II trial. Ann Hematol. 2011;90:379-387.

31. Chaurasia P, Berenzon D, Hoffman R. Chromatin-modifying agents promote the ex vivo production of functional human erythroid progenitor cells. Blood. 2011;117:4632-4641.

32. Randrianarison-Huetz V, Laurent B, Bardet V, Blobe GC, Huetz F, Dumenil D. Gfi-1B controls human erythroid and megakaryocytic differentiation by regulating TGF-beta signaling at the bipotent erythro-megakaryocytic progenitor stage. Blood. 2010;115:2784-2795.

33. Pina C, May G, Soneji S, Hong D, Enver T. MLLT3 regulates early human erythroid and megakaryocytic cell fate. Cell Stem Cell. 2008;2:264-273.

34. Bianchi E, Zini R, Salati S, et al. c-myb supports erythropoiesis through the transactivation of KLF1 and LMO2 expression. Blood. 2010;116:e99-e110.

35. Rojnuckarin P, Kaushansky K. Actin reorganization and proplatelet formation in murine megakaryocytes: the role of protein kinase calpha. Blood. 2001;97:154-161.

36. Tajika K, Ikebuchi K, Suzuki E, et al. A novel aspect of the maturational step of megakaryocytes in thrombopoiesis: bundle formation of microtubules in megakaryocytes. Exp Hematol. 1996;24:291-298.

37. Lazarides E, Woods C. Biogenesis of the red blood cell membraneskeleton and the control of erythroid morphogenesis. Annu Rev Cell Biol. 1989;5:427-452.

38. Woods CM, Lazarides E. The erythroid membrane skeleton: expression and assembly during erythropoiesis. Annu Rev Med. 1988;39: $107-122$

39. Heyworth C, Gale K, Dexter M, May G, Enver T. A GATA-2/estrogen receptor chimera functions as a ligand-dependent negative regulator of self-renewal. Genes Dev. 1999;13:1847-1860.

40. Ezoe S, Matsumura I, Nakata S, et al. GATA-2/estrogen receptor chimera regulates cytokine-dependent growth of hematopoietic cells through accumulation of $\mathrm{p} 21(\mathrm{WAF} 1)$ and $\mathrm{p} 27(\mathrm{Kip} 1)$ proteins. Blood. 2002;100:3512-3520.

41. Jankovic V, Ciarrocchi A, Boccuni P, DeBlasio T, Benezra R, Nimer SD. Id1 restrains myeloid commitment, maintaining the self-renewal capacity of hematopoietic stem cells. Proc Natl Acad Sci U S A. 2007;104:1260-1265.

42. Yeoh JS, van Os R, Weersing E, et al. Fibroblast growth factor-1 and -2 preserve long-term repopulating ability of hematopoietic stem cells in serum-free cultures. Stem Cells. 2006;24:1564-1572.

43. Bunting KD. ABC transporters as phenotypic markers and functional regulators of stem cells. Stem Cells. 2002;20:11-20.

44. Rodriguez P, Bonte E, Krijgsveld J, et al. GATA-1 forms distinct activating and repressive complexes in erythroid cells. EMBO J. 2005;24: 2354-2366. 
45. Andrews NC. The NF-E2 transcription factor. Int J Biochem Cell Biol. 1998;30:429-432.

46. Lausen J, Pless O, Leonard F, Kuvardina ON, Koch B, Leutz A. Targets of the Tal1 transcription factor in erythrocytes: E2 ubiquitin conjugase regulation by Tal1. J Biol Chem. 2010;285: 5338-5346.

47. Noguchi CT, Wang L, Rogers HM, Teng R, Jia Y. Survival and proliferative roles of erythropoietin beyond the erythroid lineage. Expert Rev Mol Med. 2008;10:e36.

48. Suenobu S, Takakura N, Inada T, et al. A role of EphB4 receptor and its ligand, ephrin-B2, in erythropoiesis. Biochem Biophys Res Commun. 2002;293:1124-1131.

49. de Wolf JT, Muller EW, Hendriks DH, Halie RM, Vellenga E. Mast cell growth factor modulates CD36 antigen expression on erythroid progenitors from human bone marrow and peripheral blood associated with ongoing differentiation. Blood. 1994;84:59-64.

50. Goldfarb AN. Megakaryocytic programming by a transcriptional regulatory loop: a circle connecting RUNX1, GATA-1, and P-TEFb. J Cell Biochem. 2009;107:377-382.
51. Orkin SH, Shivdasani RA, Fujiwara Y, McDevitt MA. Transcription factor GATA-1 in megakaryocyte development. Stem Cells. 1998; 16(suppl 2):79-83.

52. Clay D, Rubinstein E, Mishal Z, et al. CD9 and megakaryocyte differentiation. Blood. 2001;97:1982-1989.

53. Ghosh A, Li W, Febbraio M, et al. Platelet CD36 mediates interactions with endothelial cell-derived microparticles and contributes to thrombosis in mice. J Clin Invest. 2008;118:1934-1943.

54. Ishii Y, Kasukabe T, Honma Y. Induction of CCAAT/enhancer binding protein-delta by cytokinins, but not by retinoic acid, during granulocytic differentiation of human myeloid leukaemia cells. Br J Haematol. 2005;128:540-547.

55. Bradley PP, Christensen RD, Rothstein G. Cellular and extracellular myeloperoxidase in pyogenic inflammation. Blood. 1982;60:618-622.

56. Blaheta RA, Cinatl J Jr. Anti-tumor mechanisms of valproate: a novel role for an old drug. Med Res Rev. 2002;22:492-511.

57. Gottlicher M, Minucci S, Zhu P, et al. Valproic acid defines a novel class of HDAC inhibitors inducing differentiation of transformed cells. EMBO J. 2001;20:6969-6978. 


\section{Supplementary materials and methods}

Viability assay and cell cycle analysis

Viability measurement was assessed by Trypan blue exclusion assay 24 to 48 hours after VPA treatment as already described [58]. Cell cycle analysis was performed according to Fried et al. [59] at 24 to 48 hours and 6 days after VPA treatment.

\section{Morphological and immunophenotypic analysis}

The effect of VPA treatment on CD34 ${ }^{+}$cells was monitored by flow cytometric analysis (Epics XL, Coulter Electronics Inc., Hialeah, FL, USA). The CD34 antigen was monitored at days 2 and 6 of treatment using a mouse anti-CD34 monoclonal antibodies (MoAbs) conjugated to fluorescein isothiocyanate (FITC; Miltenyi, Auburn, CA, USA).

Differentiation of $\mathrm{CD}_{4} 4^{+}$cells was monitored by flow cytometric analysis of CD14, CD41, CD66b, CD15, CD163, and GPA surface antigen expression, performed at day 6 of treatment and by morphological analysis of May-Grünwald-Giemsastained cytospins, at day 9 of treatment. The images were captured by the Axioskop 40 microscope (Carl Zeiss MicroImaging Inc., Thornwood, NY, USA) by means of AxioCam HRc Digital Camera (Carl Zeiss MicroImaging Inc.) and Axiovision software 3.1 (Carl Zeiss MicroImaging Inc).

The following MoAbs were used for flow cytometric analysis: FITC-conjugated mouse anti-human CD41 MoAb, FITCconjugated mouse anti-human CD66b MoAb, phycoerythrin-conjugated mouse anti-human GPA MoAb (all from Becton Dickinson Systems, Mountain View, CA, USA), FITC-conjugated mouse anti-human CD15 MoAb, FITC-conjugated mouse anti-human CD14 MoAb, (all from Miltenyi), biotin-conjugated mouse anti-human CD163 MoAb (BMA Biomedicals, Augst, Switzerland), and streptavidin tricolors (TRITC) (Caltag Laboratories, Burlingame, CA, USA). Myeloperoxidase intracellular staining was performed using LEUCOPERM cell permeabilization kit (AbD Serotec) and FITC-conjugated mouse anti-human MPO (Immunostep Research, Salamanca, Spain).

\section{Methylcellulose clonogenic assay}

Human CFUs were cultured in methylcellulose as described previously [60]. CD34 ${ }^{+}$cells were plated in triplicate in MethoCultTM GF H4434 "Complete" Methylcellulose Medium (StemCell Technologies Inc., Vancouver, BC, Canada) containing a cocktail of recombinant human cytokines: stem cell factor $(50 \mathrm{ng} / \mathrm{mL})$, granulocyte-macrophage colony-stimulating factor $(10 \mathrm{ng} / \mathrm{mL})$, interleukin-3 $(10 \mathrm{ng} / \mathrm{mL})$, and erythropoietin $(3 \mathrm{U} / \mathrm{mL})$. After 14 days of culture at $37^{\circ} \mathrm{C}$ in a humidified atmosphere with 5\% $\mathrm{CO}_{2}$, BFU-erythroid, CFU-erythroid, CFU-granulocyte, CFU-macrophage, CFU-granulocyte-macrophage, and CFU-granulocyte/erythrocyte/macrophage/megakaryocyte were scored.

\section{Collagen clonogenic assay}

CFUs-megakaryocyte (MK) were assayed by using a commercial MK assay detection kit (MegaCult-C, StemCell Technologies Inc.). CD $34^{+}$cells were cultured at a density of $2.5 \times 10^{3} / \mathrm{mL}$ in collagen-based medium and the $0.75-\mathrm{mL}$ suspensions were seeded per chamber of a double-chamber slide. This collagen-based medium system contains $1.1 \mathrm{mg} / \mathrm{mL}$ collagen, $1 \%$ bovine serum albumin, $0.01 \mathrm{mg} / \mathrm{mL}$ bovine pancreatic insulin, $0.2 \mathrm{mg} / \mathrm{mL}$ human transferrin (iron saturated), and the human recombinant cytokines: $50 \mathrm{ng} / \mathrm{mL}$ thrombopoietin, $10 \mathrm{ng} / \mathrm{mL}$ interleukin-3, and $10 \mathrm{ng} / \mathrm{mL}$ interleukin- 6 . The chamber slides were incubated at $37^{\circ} \mathrm{C}$ for 12 days and then fixed for $20 \mathrm{~min}$ in 1:3 methanol/acetone. MK colonies were stained using a primary monoclonal anti-CD41 (GPIIb/IIIa) antibody and then identified by using an alkaline phosphatase/naphthol detection system (all from StemCell Technologies Inc.). Cells were counterstained with Evans Blue, causing the cell nuclei to turn blue, regardless of lineage. CD41-positive colonies were scored as CFU-MK. Values are reported as \pm 2 standard error of mean from five independent experiments.

\section{RNA extraction and microarray analysis}

Total cellular RNA was extracted after 48 hours of treatment from $0.5 \times 10^{6}$ cells of each sample using RNeasy Micro kit (Qiagen, Valencia, CA, USA) following the protocol supplied by the manufacturer. Disposable RNA chips (Agilent RNA 6000 Nano LabChip kit; Agilent Technologies, Waldbrunn, Germany) were used to determine the purity/integrity of RNA samples using Agilent 2100 Bioanalyzer. NanoDrop ND-1000 spectrophotometer (NanoDrop Technologies, Wilmington, DE, USA) was used to evaluate the RNA sample concentration, and 260/280 and 260/230 nm ratios were considered to verify the purity of total RNA. RNAs originating from five different experiments were pooled in order to obtain at least $2 \mu \mathrm{g}$ per sample.

One-cycle target labeling assays, as well as the Affymetrix Human HG-U133A GeneChip arrays hybridization, staining, and scanning, were performed, using Affymetrix standard protocols (Affymetrix, Santa Clara, CA, USA) as described previously [61].

The GeneChip Operating Software absolute analysis algorithm was used to determine the amount of a transcript messenger RNA (Signal), while the GeneChip Operating Software comparison analysis algorithm was used in order to compare gene expression levels between two samples. 
Present genes were selected as the sequences showing the Detection call "P" and Signal $>100$ at least in one sample. Differentially expressed genes were selected as the sequences showing a Change call "I" or "D" and Signal Log Ratio $\geq 1$ or $\leq-1$ in the pair-wise comparisons between VPA CD34 $4^{+}$and untreated (CTR) CD34 $4^{+}$cells.

All data have been deposited in the Gene Expression Omnibus MIAME compliant public database at http://www.ncbi.nlm. nih.gov/geo/query/acc.cgi?acc $=$ GSE31283.

DAVID 6.7 software (http://david.abcc.ncifcrf.gov/) was used to examine selected lists of genes in order to identify overrepresentation of functional classes according to GO classification.

To validate microarray data, we selected a set of eight differentially expressed genes involved in self-renewal and differentiation processes, which were monitored by RTQ-PCR. Complementary DNA was reverse-transcribed from total RNA (100 ng per sample) using High Capacity cDNA Archive Kit (Applied Biosystems, Foster City, CA, USA; https://www. appliedbiosystems.com). TaqMan PCR was carried out using the TaqMan Fast Universal PCR Master Mix and TaqMan gene expression assays (Applied Biosystems) (Supplementary Table E3), by means of ABI Prism 7900 HT Fast Real-Time PCR System (Applied Biosystems). Assays were performed in triplicate. Gene expression profiling was achieved using the comparative cycle threshold (CT) method of relative quantitation using glyceraldehyde-3-phosphate dehydrogenase as the housekeeping gene. To normalize data, $\Delta \Delta \mathrm{CT}$ was calculated for each sample using the mean of its $\Delta \mathrm{CT}$ values subtracted from the mean $\Delta \mathrm{CT}$ value measured in the CTR sample, set as a calibrator; relative quantitation [62] value was expressed as $2-\Delta \Delta \mathrm{CT}$.

\section{Chromatin immunoprecipitation assay}

CD $34^{+}$cells were treated with VPA as indicated here for 24 hours. Chromatin immunoprecipitation assay was performed as reported by Lang et al. [63], with some modifications. After crosslinking in $1 \%$ formaldehyde, VPA CD34 ${ }^{+}$and CTR cells $\left(2 \times 10^{6}\right.$ cells) were resuspended in $3 \mathrm{~mL}$ lysis buffer $(5 \mathrm{mM}$ PIPES, $85 \mathrm{mM} \mathrm{KCl}, 0.5 \%$ NP-40, protease inhibitors; Roche, Indianapolis, IN, USA, and $1 \mathrm{mM}$ phenylmethylsulfonyl fluoride) and incubated on ice for $10 \mathrm{~min}$, then disrupted with a Dounce homogenizer. Nuclei were pelleted and resuspended in $1 \mathrm{~mL}$ sonication buffer $(0.1 \%$ sodium dodecyl sulfate, $10 \mathrm{mM}$ EDTA [pH 8], $50 \mathrm{mM}$ Tris [pH 8], protease inhibitors [Roche], and $1 \mathrm{mM}$ phenylmethylsulfonyl fluoride) and incubated on ice for $10 \mathrm{~min}$. Chromatin with an average size of 500 to $1000 \mathrm{bp}$ was produced by sonication. Debris was cleared by centrifugation. Chromatin ( $200 \mu \mathrm{L}$ for each sample) was diluted twofold into RIPA buffer (10 mM Tris $\mathrm{HCl}$ [pH 8], $1 \mathrm{mM}$ EDTA [pH 8], $0.5 \mathrm{mM}$ EGTA, $1 \%$ Triton X-100, 0.1\% Na-deoxycholate, $0.1 \%$ sodium dodecyl sulfate, $140 \mathrm{mM} \mathrm{NaCl}, 1 \mathrm{mM}$ phenylmethylsulfonyl fluoride, and protease inhibitors [Roche]) and precleared with Protein A Sepharose CL-4B (GE Healthcare, Uppsala, Sweden), then immunoprecipitated with (Acetyl H4 sample) or without (No Antibody sample) mouse polyclonal anti-acetyl histone $\mathrm{H} 4$ antibody (catalog \#06-866; Upstate, Lake Placid, NY, USA) overnight at $4{ }^{\circ} \mathrm{C}$ with rotation. A negative control (named IgG CTR) sample incubated with an isotype-matched nonspecific antibody (Upstate) was included. Protein A Sepharose CL-4B was precleared in RIPA buffer with $1 \mu \mathrm{g} / \mu \mathrm{L}$ Salmon Sperm DNA and $1 \mu \mathrm{g} / \mu \mathrm{L}$ bovine serum albumin overnight at $4^{\circ} \mathrm{C}$ with rotation and then washed twice in RIPA buffer. Immune complexes were collected by incubation with precleared Protein A Sepharose for 2 hours with rotation at $4^{\circ} \mathrm{C}$. The supernatant fraction of the No Antibody sample was collected as total input chromatin. The Protein A Sepharose/antibody/chromatin complex was washed 10-fold with RIPA buffer, then once with $\mathrm{LiCl}$ buffer $(250 \mathrm{mM} \mathrm{LiCl}, 0.5 \% \mathrm{NP} 40,0.5 \% \mathrm{Na}$ deoxycholate, $1 \mathrm{mM}$ EDTA, $10 \mathrm{mM}$ Tris $\mathrm{HCl}[\mathrm{pH} 8])$ and TE buffer (1 mM EDTA, $10 \mathrm{mM}$ Tris $\mathrm{HCl}[\mathrm{pH} 8])$, respectively. Beads were resuspended in 100 $\mu \mathrm{L}$ TE buffer. Samples were incubated with RNase A overnight at $65^{\circ} \mathrm{C}$, then with $0.5 \%$ sodium dodecyl sulfate and 0.5 $\mathrm{mg} / \mathrm{mL}$ proteinase $\mathrm{K}$ at $50^{\circ} \mathrm{C}$ for 3 hours. Immunoprecipitated DNA samples were isolated by phenol-chloroform extraction, precipitated in ice-cold ethanol at $-20^{\circ} \mathrm{C}$. Immunoprecipitated DNA samples were resuspended in $30 \mu \mathrm{L} \mathrm{H}_{2} \mathrm{O}$ and fractions used for semi-quantitative PCR (EuroTaq; Euroclone, Milano, Italy). Specific primers for GATA2, MLLT3, and GFI1B were designed to amplify the proximal promoter regions (Supplementary Table E4). PCR parameters were: denaturation at $95^{\circ} \mathrm{C}$ for 30 seconds and annealing at $62^{\circ} \mathrm{C}$ for 30 seconds, followed by elongation at $72^{\circ} \mathrm{C}$ for 45 seconds. PCR products were analyzed by $2 \%$ agarose-ethidium bromide gel electrophoresis. Each experiment was performed three times with independent chromatin extracts. Data shown are for 30 PCR cycles.

\section{siRNA transfection}

The electroporation of $\mathrm{CD} 34^{+}$stem/progenitor cells was performed using the Amaxa Nucleofector Technology as previously described [64]. A mix of 3 Silencer Select Pre-designed siRNAs targeting human GFI1B or MLLT3 (Supplementary Table E2) was used (Ambion). Each sample was electroporated three times, once every 24 hours. For each electroporation, $5 \times 10^{5}$ $\mathrm{CD}^{+} 4^{+}$cells were resuspended in $100 \mu \mathrm{L}$ human CD34 ${ }^{+}$Nucleofection Solution (Amaxa Biosystem), containing $3 \mu \mathrm{g}$ siRNA and pulsed with the program U-01. To exclude nonspecific effects of siRNA nucleofection, for each experiment, one sample transfected with a nontargeting siRNA (NegCTR; Silencer Select Negative Control \#2 siRNA; Ambion) was performed. First nucleofection was performed after 24 hours of preactivation in the culture condition described here. Cells were treated with $400 \mu \mathrm{g} / \mathrm{mL}$ VPA immediately after first electroporation. 


\section{References}

58. Humpe A, Beck C, Schoch R, Kneba M, Horst HA. Establishment and optimization of a flow cytometric method for evaluation of viability of CD34+ cells after cryopreservation and comparison with trypan blue exclusion staining. Transfusion. 2005;45:1208-1213.

59. Fried J, Perez AG, Clarkson BD. Rapid hypotonic method for flow cytofluorometry of monolayer cell cultures. Some pitfalls in staining and data analysis. J Histochem Cytochem. 1978;26:921-933.

60. Manfredini R, Zini R, Salati S, et al. The kinetic status of hematopoietic stem cell subpopulations underlies a differential expression of genes involved in self-renewal, commitment, and engraftment. Stem Cells. 2005;23:496-506.

61. Bianchi E, Zini R, Salati S, et al. c-myb supports erythropoiesis through the transactivation of KLF1 and LMO2 expression. Blood. 2010;116:e99-e110.

62. Gul H, Marquez-Curtis LA, Jahroudi N, Lo J, Turner AR, Janowska-Wieczorek A. Valproic acid increases CXCR4 expression in hematopoietic stem/progenitor cells by chromatin remodeling. Stem Cells Dev. 2009;18:831-838.

63. Lang G, White JR, Argent-Katwala MJ, Allinson CG, Weston K. Myb proteins regulate the expression of diverse target genes. Oncogene. 2005;24: 1375-1384.

64. Salati S, Zini R, Bianchi E, et al. Role of CD34 antigen in myeloid differentiation of human hematopoietic progenitor cells. Stem Cells. 2008;26: 950-959.
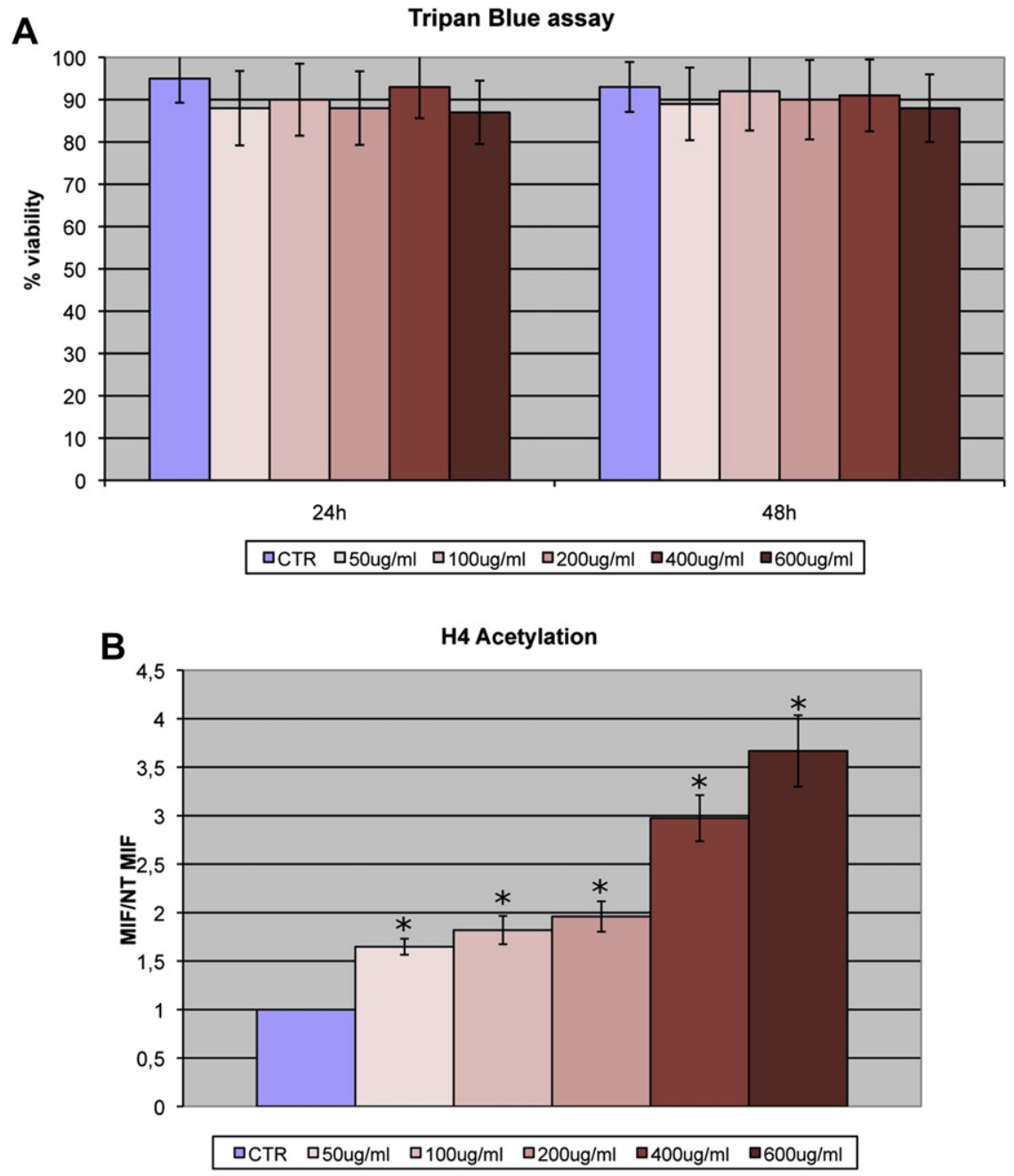

Supplementary Figure E1. (A) Evaluation of cell viability by Trypan blue assay. Results of statistical analysis on percent of viable cells after 24 and 48 hours of VPA treatment. Data come from three independent experiments. Values are reported as mean \pm 2 standard error of mean (SEM). The $p$ values were not significant $(p>0.05)$ in all pair-wise comparisons. (B) Flow cytometric analysis of tetracetylated histone H4 in CD34 ${ }^{+}$CTR and VPA-treated cells. Results of statistical analysis on the percentage of positive cells for tetracetylated histone H4 performed at 48 hours of VPA treatment. Values are reported as mean \pm 2 standard error of mean. $* p<0.05$ vs CTR. Results come from three independent experiments. $\mathrm{h}=\mathrm{hours}$; MIF $=$ mean intensity fluorescence. 


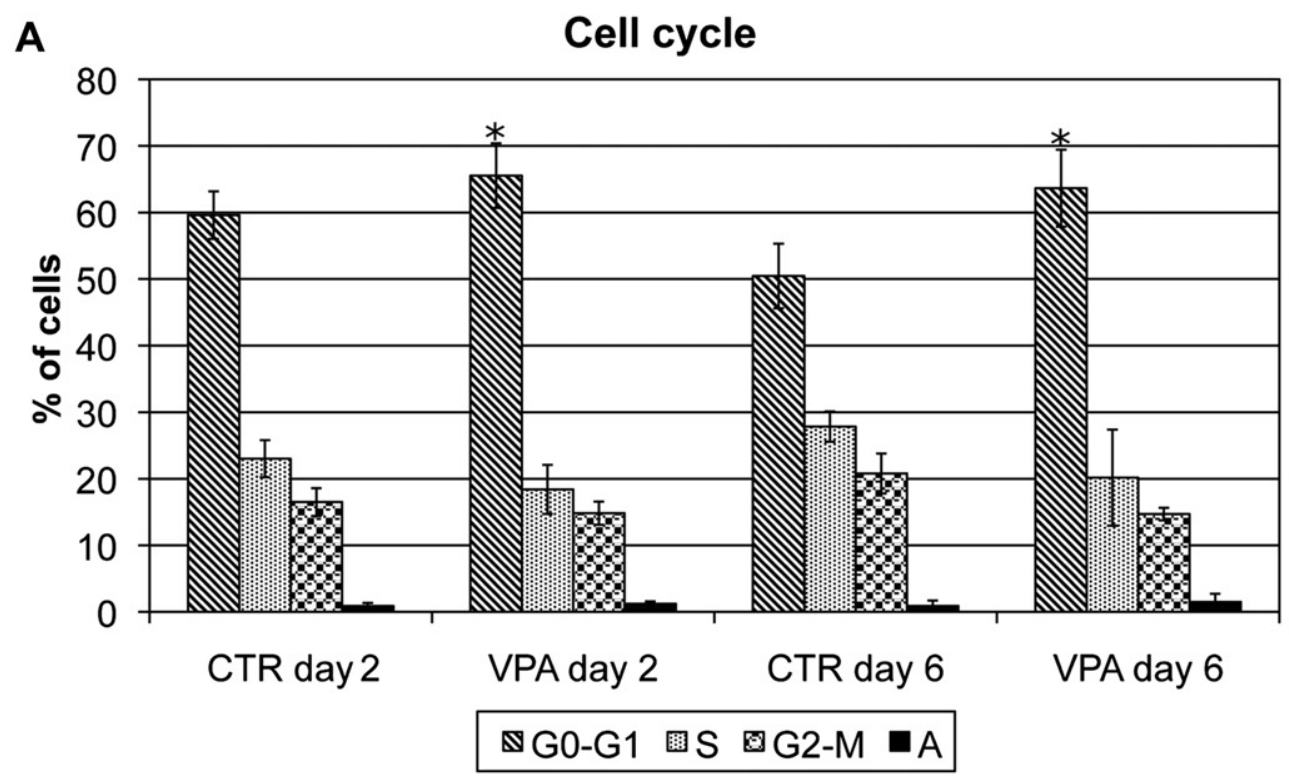

B

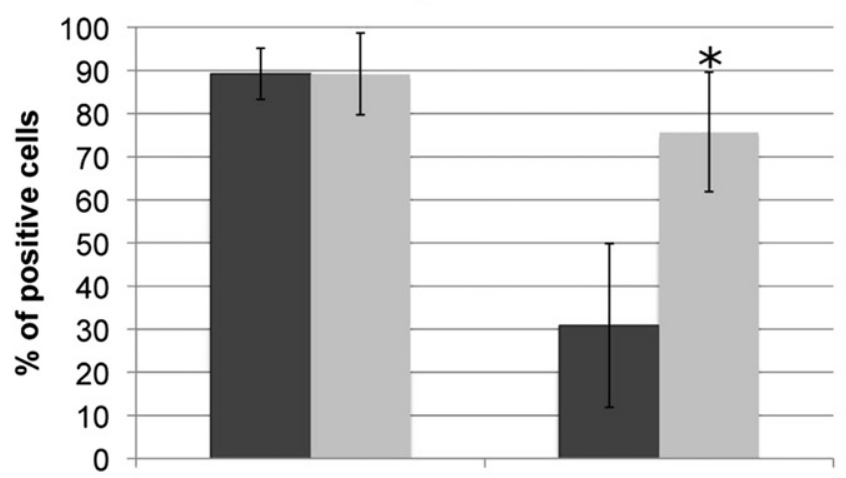

day 2

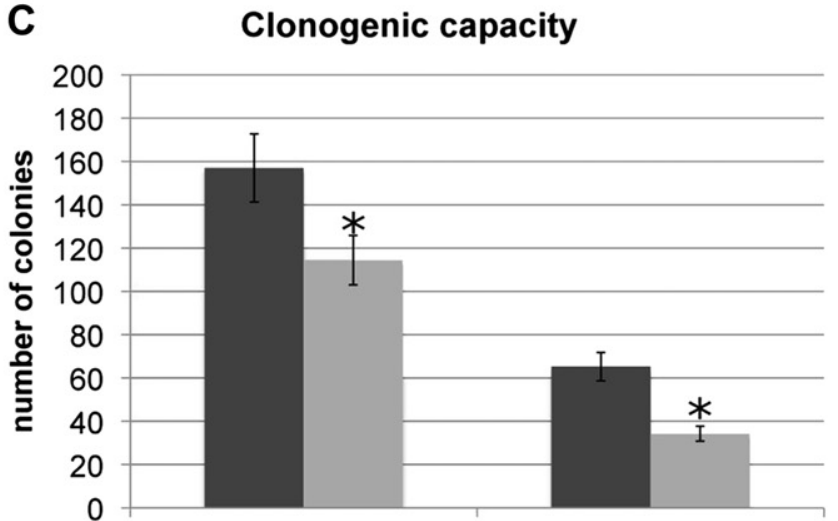

day 2 day 6

$\square$ CTR CD34+ VPA CD34+

CTR CD34+ IVA CD34+

Supplementary Figure E2. Clonogenic potential of VPA CD34 ${ }^{+}$cells after 48 hours and 6 days of treatment. (A) Evaluation of cell cycle distribution performed by propidium iodide (PI) staining in CD34 ${ }^{+}$CTR and VPA-treated cells. Results are shown as percent of cells in the different phases of cell cycle. (B) Results of statistical analysis on the percent of positive cells for CD34 antigen performed by flow cytometry. (C) Clonogenic capacity of CTR and VPAtreated CD34 ${ }^{+}$cells (count of total colonies). Results of statistical analysis of methylcellulose-based clonogenic assay in cells plated after 48 hours and 6 days of treatment with VPA and scored after 14 days. Values are reported as mean \pm 2 standard error of mean (SEM). ${ }^{*} p<0.05$ vs CTR. Results come from three independent experiments. $A=$ apoptotic hypodiploid cells; $G_{0}-G_{1}=G_{0}-G_{1}$ phase cells; $G_{2}-M=G_{2}-M$ phase cells; $S=S$ phase cells. 
Supplementary Table E1A. GO categories increased in VPA treated $\mathrm{CD} 34+$ cells

\begin{tabular}{|c|c|}
\hline Term & $p$ \\
\hline GO:0032502 developmental process & $6.80 \mathrm{E}-07$ \\
\hline GO:0030154 cell differentiation & $9.13 \mathrm{E}-07$ \\
\hline GO:0048869 cellular developmental process & $9.13 \mathrm{E}-07$ \\
\hline GO:0032989 cellular structure morphogenesis & $1.72 \mathrm{E}-05$ \\
\hline GO:0048468 cell development & 4.31E-05 \\
\hline GO:0008285 negative regulation of cell proliferation & $1.05 \mathrm{E}-04$ \\
\hline GO:0007275 multicellular organismal development & $1.12 \mathrm{E}-04$ \\
\hline GO:0048856 anatomical structure development & $2.12 \mathrm{E}-04$ \\
\hline GO:0040012 regulation of locomotion & 2.29E-04 \\
\hline GO:0040011 locomotion & $2.49 \mathrm{E}-04$ \\
\hline GO:0030334 regulation of cell migration & $5.21 \mathrm{E}-04$ \\
\hline GO:0007010 cytoskeleton organization and biogenesis & $5.31 \mathrm{E}-04$ \\
\hline GO:0032501 multicellular organismal process & 9.37E-04 \\
\hline GO:0051270 regulation of cell motility & 0.001086606 \\
\hline GO:0016192 vesicle-mediated transport & 0.002259532 \\
\hline GO:0042221 response to chemical stimulus & 0.002902522 \\
\hline $\begin{array}{l}\text { GO:0000904 cellular morphogenesis during } \\
\text { differentiation }\end{array}$ & 0.00320257 \\
\hline GO:0051674 localization of cell & 0.004747889 \\
\hline GO:0006928 cell motility & 0.004747889 \\
\hline GO:0006996 organelle organization and biogenesis & 0.005201906 \\
\hline GO:0051179 localization & 0.005430699 \\
\hline GO:0006897 endocytosis & 0.005851078 \\
\hline GO:0012501 programmed cell death & 0.006858115 \\
\hline GO:0000902 cell morphogenesis & 0.00932736 \\
\hline GO:0016044 membrane organization and biogenesis & 0.01077055 \\
\hline GO:0050793 regulation of developmental process & 0.011874058 \\
\hline GO:0007417 central nervous system development & 0.012027378 \\
\hline GO:0016477 cell migration & 0.015673394 \\
\hline GO:0030041 actin filament polymerization & 0.015741481 \\
\hline GO:0048469 cell maturation & 0.015792225 \\
\hline $\begin{array}{l}\text { GO:0008154 actin polymerization and/or } \\
\text { depolymerization }\end{array}$ & 0.01582865 \\
\hline GO:0042493 response to drug & 0.017732199 \\
\hline GO:0035270 endocrine system development & 0.018714076 \\
\hline GO:0016055 Wnt receptor signaling pathway & 0.019201003 \\
\hline GO:0043067 regulation of programmed cell death & 0.020295468 \\
\hline GO:0009653 anatomical structure morphogenesis & 0.023413321 \\
\hline GO:0030100 regulation of endocytosis & 0.02343298 \\
\hline GO:0008283 cell proliferation & 0.025228803 \\
\hline $\begin{array}{l}\text { GO:0030036 actin cytoskeleton organization } \\
\text { and biogenesis }\end{array}$ & 0.025295274 \\
\hline $\begin{array}{l}\text { GO:0008277 regulation of G-protein coupled } \\
\text { receptor protein signaling pathway }\end{array}$ & 0.028736606 \\
\hline GO:0030029 actin filament-based process & 0.035909954 \\
\hline GO:0030030 cell projection organization and biogenesis & 0.043518012 \\
\hline GO:0048858 cell projection morphogenesis & 0.043518012 \\
\hline GO:0009887 organ morphogenesis & 0.045397503 \\
\hline
\end{tabular}

Supplementary Table E1B. GO categories decreased in VPA-treated CD34+ cells

\begin{tabular}{|c|c|}
\hline Term & $p$ Value \\
\hline GO:0006955 immune response & $9.78 \mathrm{E}-09$ \\
\hline GO:0002376 immune system process & $7.71 \mathrm{E}-10$ \\
\hline $\begin{array}{l}\text { GO:0008284 positive regulation of cell } \\
\text { proliferation }\end{array}$ & $9.06 \mathrm{E}-10$ \\
\hline GO:0050896 response to stimulus & $4.22 \mathrm{E}-11$ \\
\hline GO:0008380 RNA splicing & $6.76 \mathrm{E}-11$ \\
\hline $\begin{array}{l}\text { GO:0002819 regulation of adaptive } \\
\text { immune response }\end{array}$ & $2.00 \mathrm{E}-12$ \\
\hline GO:0006952 defense response & $3.41 \mathrm{E}-12$ \\
\hline GO:0006397 mRNA processing & 0.00136345883081106 \\
\hline GO:0016071 mRNA metabolic process & 0.00329304855689849 \\
\hline GO:0002443 leukocyte mediated immunity & 0.00549122165753843 \\
\hline GO:0042127 regulation of cell proliferation & 0.0087383613540313 \\
\hline GO:0050900 leukocyte migration & 0.0104161146738888 \\
\hline GO:0002440 production of molecular & 0.0104161146738888 \\
\hline
\end{tabular}

mediator of immune response

GO:0006954 inflammatory response

GO:0016064 immunoglobulin mediated immune response

GO:0019724 B cell mediated immunity

GO:0006950 response to stress

GO:0009605 response to external stimulus

GO:0008283 cell proliferation

GO:0045321 leukocyte activation

GO:0002252 immune effector process

GO:0002821 positive regulation of adaptive

immune response

GO:0050865 regulation of cell activation

GO:0042742 defense response to bacterium

GO:0002449 lymphocyte mediated immunity

GO:0006928 cell motility

GO:0051674 localization of cell

0.013437579323228144

0.026505907712935338

0.02835487616050515

0.028680005111878626

0.03088583514684647

0.03227714039778802

0.03502104536588843

0.04141566045384332

0.04141566045384332

0.043754465833738085

0.043754465833738085

0.04713580716344888

0.04740580932525914

0.04740580932525914

Supplementary Table E2. GFI1B and MLLT3 siRNA sequences

\begin{tabular}{lllr}
\hline siRNA ID & Target & Sequence (Sense) & $\begin{array}{r}\text { Targeted } \\
\text { exon(s) }\end{array}$ \\
\hline s15850 & GFI1B & CAGCUUGUUUUGAGACUCAtt & 6 \\
s15851 & GFI1B & GGACCAACCUCAAACGAGAtt & 3 \\
s15852 & GFI1B & CCCUGUCCUUAGCACUCUAtt & 3 \\
s8826 & MLLT3 & GCAGAUCGUGAACCUUAUAtt & 10,11 \\
s8827 & MLLT3 & GCAGAGUUAGCUUAAGUGAtt & 7,8 \\
s8828 & MLLT3 & GGAGAGGCCUGUAAAUAGAtt & 7 \\
\hline
\end{tabular}


Supplementary Table E3. TaqMan gene expression assay ID for RTQPCR

TaqMan gene expression assays (Applied Biosystems)

\begin{tabular}{ll}
\hline GAPDH & Hs99999905_m1 \\
CDKN1A & Hs00355782_m1 \\
ELA2 & Hs00236952_m1 \\
GATA1 & Hs00231112_m1 \\
GATA2 & Hs00231119_m1 \\
GFI1B & Hs00180261_m1 \\
ID1 & Hs00704053_s1 \\
MLLT3 & Hs00180312_m1 \\
RUNX1 & Hs00231079_m1
\end{tabular}

Supplementary Table E4. PCR primers for CHIP analysis

\begin{tabular}{lllr}
\hline \multicolumn{4}{c}{ Primers } \\
\hline GATA2 & DP & $5^{\prime}$ GTGAGAGTCTGCCCCAAGGAG 3' & -692 \\
& RP & $5^{\prime}$ CCCACTTCCAGGAGTGCTCAC 3' & -400 \\
GFI1B & DP & $5^{\prime}$ GAGCAATGACTTCCCTATGCAAA 3' & -351 \\
& RP & $5^{\prime}$ CCTCTTCTGTTCCCCTCCCTG 3' & -44 \\
MLLT3 & DP & $5^{\prime}$ CCACAGAAATACGTGGTGGAAAG 3' & -427 \\
& RP & $5^{\prime}$ GGGAGCTCGAAAGAGCCAATCA 3' & -115 \\
\hline
\end{tabular}

